\title{
The Adverse Impact of Incense Smoke on Human Health: From Mechanisms to Implications
}

\author{
Chiang-Wen Lee, ${ }^{1-4, *}$ Thi Thuy Tien Vo, ${ }^{5, *}$ \\ Yinshen Wee, ${ }^{6}$ Yao-Chang Chiang, (iD) ${ }^{1,2}$ \\ Miao-Ching Chi, ${ }^{7-9}$ Min-Li Chen, ${ }^{10,11}$ \\ Lee-Fen Hsu, ${ }^{9,12}$ Mei-Ling Fang, ${ }^{13,14}$ \\ Kuan-Han Lee, (D) ${ }^{15}$ Su-Er Guo, (ID ${ }^{11}$ \\ Hsin-Chung Cheng, ${ }^{5,16}$ I-Ta Lee (iD) ${ }^{5}$
}

'Department of Nursing, Division of Basic Medical Sciences, Chronic Diseases and Health Promotion Research Center and Research Center for Chinese Herbal Medicine, Chang Gung University of Science and Technology, Puzi City, Chiayi County, Taiwan; ${ }^{2}$ Department of Orthopaedic Surgery, Chang Gung Memorial Hospital, Puzi City, Chiayi County, Taiwan; ${ }^{3}$ Department of Safety Health and Environmental Engineering, Ming Chi University of Technology, New Taipei City, Taiwan; ${ }^{4}$ College of Medicine, Chang Gung University, Taoyuan City, Taiwan; ${ }^{5}$ School of Dentistry, College of Oral

Medicine, Taipei Medical University, Taipei, Taiwan

${ }^{6}$ Department of Pathology, University of Utah, Salt Lake City, UT, USA; ${ }^{7}$ Chronic Disease and Health Promotion Research Center, Chang Gung University of Science and Technology, Puzi City, Chiayi County, Taiwan; ${ }^{8}$ Division of Pulmonary and Critical Care Medicine, Chiayi Chang Gung

Memorial Hospital, Puzi City, Chiayi County, Taiwan; 'Department of Respiratory Care, Chang Gung University of Science and Technology, Puzi City, Chiayi County, Taiwan; ${ }^{10}$ Department of Nursing, Chang Gung Memorial Hospital, Puzi City, Chiayi County, Taiwan; " Graduate Institute of Nursing, Chang Gung University of Science and Technology, Puzi City, Chiayi County, Taiwan: ${ }^{12}$ Division of Neurosurgery, Department of Surgery, Chang Gung Memorial Hospital, Puzi City, Chiayi County, Taiwan; ${ }^{13}$ Center for Environmental Toxin and Emerging-Contaminant Research, Cheng Shiu University, Kaohsiung, Taiwan; ${ }^{14}$ Super Micro Research and Technology Center, Cheng Shiu University, Kaohsiung, Taiwan; ${ }^{15}$ Department of Pharmacy, Chia Nan University of Pharmacy and Science, Tainan, Taiwan; ${ }^{16}$ Department of Dentistry, Taipei Medical University Hospital, Taipei, Taiwan

*These authors contributed equally to this work

Correspondence: I-Ta Lee

School of Dentistry, College of Oral

Medicine, Taipei Medical University, 250

Wuxing St, Taipei, II03I, Taiwan

Tel +886-2-2736166I ext. 5162

Fax +886-2-27362295

Email itlee0128@tmu.edu.tw

\begin{abstract}
Incense burning is a very popular activity in daily life among many parts all over the world. A growing body of both epidemiological and experimental evidences has reported the negative effects of incense use on human well-being, posing a potential threat at public significance. This work is a comprehensive review that covers the latest findings regarding the adverse impact of incense smoke on our health, providing a panoramic visualization ranging from mechanisms to implications. The toxicities of incense smoke come directly from its harmful constituents and deposition capacity in the body. Besides, reactive oxygen speciesdriven oxidative stress and associated inflammation seem to be plausible underlying mechanisms, eliciting various unfavorable responses. Although our current knowledge remains many gaps, this issue still has some important implications.
\end{abstract}

Keywords: incense burning, oxidative stress, inflammation, cancer, toxicants

\section{Introduction}

The word incense comes from Latin incendere meaning "to burn". In fact, incense is an entity that can be burned to release aromatic smoke. Incense burning has been a traditional and common practice in many parts across the world, especially in Eastern region, for various purposes since ancient time. Incense burning has become a daily routine and an indispensable ritualistic practice in some religions, such as Buddhism, Taoism, and Hinduism. ${ }^{1}$ Thus, there has been an extensive practice of incense burning in temples, monasteries, mosques, and household settings, for divine worshipping and ancestor veneration. Furthermore, the burning of incense has been adopted into human daily life for other purposes, such as deodorant, aromatherapy, and meditation, among others. ${ }^{2,3}$ Collectively, these practices lead to the pervasive uses of incense in modern societies up to date. The global consumption of incense was estimated to exceed 200 million tons per year, where Asia is the largest market. ${ }^{4,5}$ A report by Taiwan Environmental Protection Agency in 2003 indicated that a total of 28.7 metric tons of incense were burned in 92 temples in Kao-Hsiong City, ${ }^{6}$ contributing to approximately 3580 tons of annual consumption of incense in temples in Taiwan. ${ }^{7}$ It is even expected that larger quantities of incense may be burned during the climax of religious rituals, big festivals, and special ceremonies and occasions. Beyond the religious and public places, it was reported that nearly $80 \%$ among Chinese burn the incense at home every day and over $90 \%$ of population has been practicing the incense burning for more than 20 years. ${ }^{8}$ Similarly, it was calculated that incense is burned at least once a week in $86 \%$ of households in United Arab Emirates. ${ }^{9}$ These data suggest that the 


\section{Graphical Abstract}

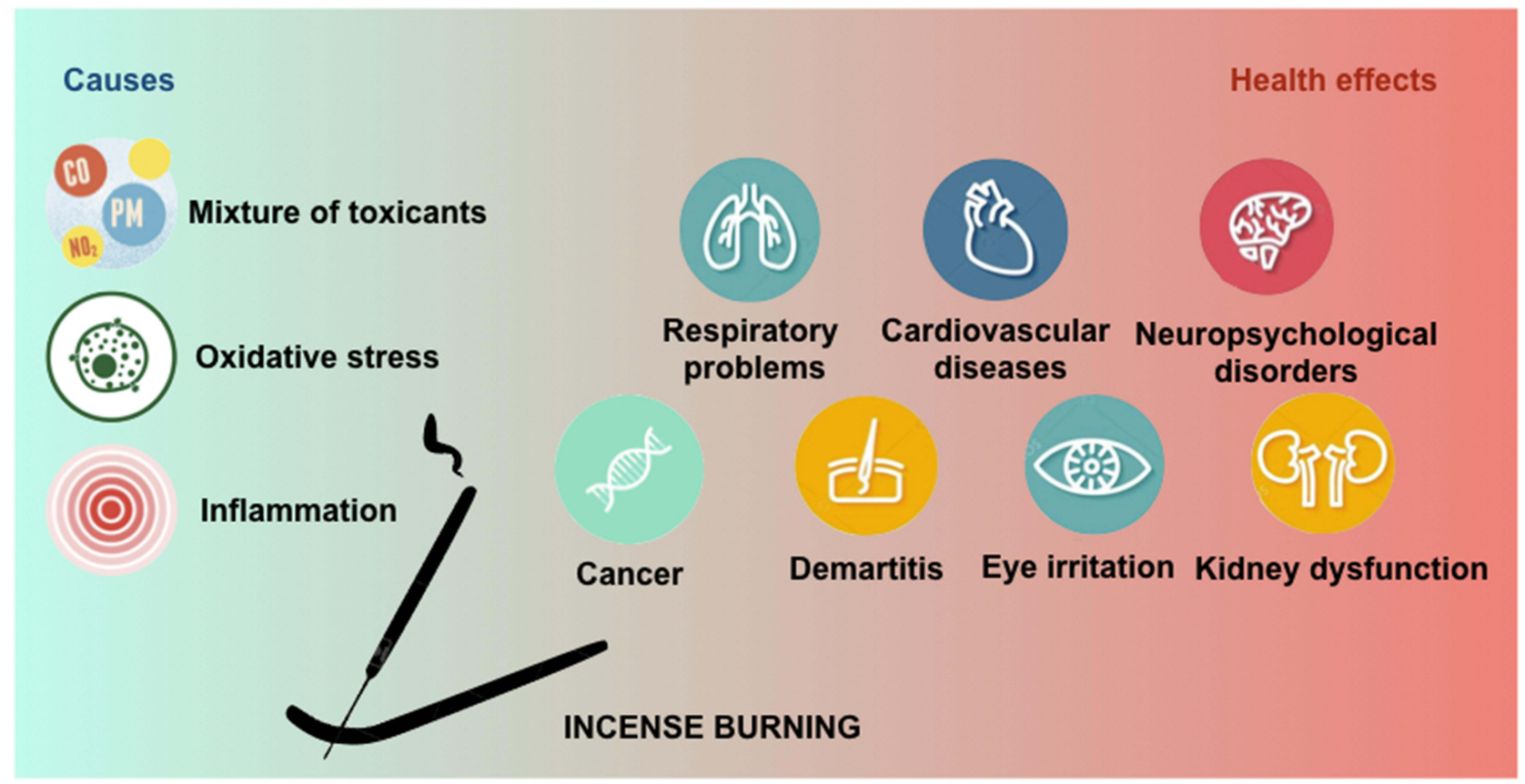

domestic incense burning also dominates a huge amount of consumed incense. Unfortunately, it was stated that incense undergoes a slow continuous burn with incomplete combustion, ${ }^{10}$ leading to the emission of smoke whose harmful constituents would be discussed later. ${ }^{11}$ With the significant consumption of incense as mentioned above, incense burning may represent a major source of both outdoor and indoor air pollution. In addition, incense smoke released during the burning process can be inhaled into the human body, and it is considered as comparable as or even more harmful than passive smoking. ${ }^{2}$ In fact, there have been growing evidences indicating the association between exposure to incense smoke and the increased risk of numerous health issues, such as respiratory problems, cardiovascular diseases, and even cancer. ${ }^{12-14}$ Now that most people in the world aware of the deleterious impact of smoking, it is time for us to consider another potential threat to public health and comfort risen from the old-age custom of burning incense in ritual places and at homes. However, still much more inquiries about the adverse effects of incense burning on human health remain, particularly the underlying mechanisms. Therefore, the objectives of this work are to shed light on the detrimental constituents of smoke derived from incense burning, and to summarize the current status of knowledge on the association between incense burning and health risks, with a focus on oxidative stress and associated inflammation as possible underlying mechanisms. Also, plausible implications for public health management are discussed. Through the current review, it is expected to unveil the remaining gaps and further steps required for the illumination of this emerging issue in the future.

\section{The Health Risks from Incense Burning: The Consonance of Harmful Constituents in the Incense Smoke}

There is a variety of commercially available forms of incense, including sticks, joss sticks, cones, coils, powders, rope, rocks or charcoal, and smudge bundles. ${ }^{2}$ Among them, incense sticks, whose base is a slender piece of wood or bamboo to which incense powder is attached, ${ }^{2}$ have been widely and commonly used in many parts worldwide, such as the Indian subcontinent, Asian countries, and the United States. ${ }^{15,16}$ Incense stick powder 
is generally made from a combination of fragrance material, wood chips, coal powder or potassium nitrate, and adhesives. ${ }^{10,16}$ During its burning process, incense generates smoke whose characterization has indicated that the gaseous phase consists of carbon dioxide, carbon monoxide, sulfur dioxide, formaldehyde, nitrogen dioxide, polycyclic aromatic compounds, volatile organic compounds, as well as particle phase defined as particulate matter. ${ }^{17-19}$ The incense emission of deleterious concern can be classified into inorganic gaseous products, particulate matter, and organic compounds, as presented following. Individuals who are under the exposure to incense burning may inhale the whole complex mixture of irritants and toxicants, posing a significant risk for human health. On the other hand, as coal powder whose function is to facilitate the smoother burning is an ingredient for the manufacturing of incense sticks, incense can leave a gray to an earthen color leftover called incense sticks ash when it is lighted. ${ }^{3,16,20}$ The complete combustion of an incense stick can produce the ash up to one-tenth of its weight. ${ }^{10}$ Importantly, the analysis of incense sticks ash has revealed the presence of many toxic heavy metals as well as oxides including calcium oxides, silica, alumina, ferrous, potassium oxide, phosphorus oxide, magnesium oxide, and oxides of trace elements. Further observation of elemental composition has shown the highest percentage of carbon, possibly due to the incomplete burning, soots, and volatile organic matters present in the incense sticks. ${ }^{10}$ The structural, chemical, and elemental properties as well as the potential applications of incense sticks ash have been well reported in some recent studies. ${ }^{10,16,20}$ However, the research regarding the characteristics and implications of incense sticks ash is still ongoing, and it is beyond the theme of the current review.

\section{Inorganic Gaseous Products}

According to existing evidences regarding the emission characterization of incense burning, three major inorganic gases identified in the incense smoke include carbon monoxide (CO), nitrogen oxides (NOx), and sulfur dioxide $\left(\mathrm{SO}_{2}\right)$. Firstly, $\mathrm{CO}$ which is a colorless, odorless, tasteless, yet deleterious gas is an inevitable consequence of combustion. ${ }^{21}$ Thus, it is not uncommon to detect this gaseous product during incense burning as an incomplete combustion. By using the experimental test chamber, $\mathrm{CO}$ emission factor was calculated to vary between 110 $120 \mathrm{mg} / \mathrm{g}$ of incense. ${ }^{22}$ Moreover, the peak levels of CO emitted from several common types of incense with different origins were found to exceed the Recommended Indoor Air Quality Objectives for Office Buildings and Public Spaces in Hong Kong (HKIAQO) standard, two of which were even greater than National Ambient Air Quality Standards (NAAQS) established by the United States Environmental Protection Agency (US EPA) for 1-h CO of $35 \mathrm{ppm}$. The highest emission rate and emission factor for CO were observed up to $794.7 \mathrm{mg} / \mathrm{h}$ and $227.7 \mathrm{mg} / \mathrm{g}$ of incense, respectively, depending on the type of incense. ${ }^{18}$ So far, the concerns about the potential health effects of exposure to $\mathrm{CO}$ have been well studied through numerous epidemiological and experimental investigations. The signs and symptoms of $\mathrm{CO}$ poisoning are generally non-specific among individuals, that range from headache, nausea and vomiting, vertigo, alteration in consciousness, and subjective weakness to confusion, myocardial infarction, respiratory failure, loss of consciousness, and even death, as mainly determined by the concentration and duration of exposure. ${ }^{23}$ The major mechanism of $\mathrm{CO}$ toxicity is attributed to its greatly high affinity for hemoglobin in the blood which is the vital oxygen deliver in the body, resulting in the deprivation of adequate oxygen supply called hypoxia. Thus, tissues with a greater requirement for oxygen such as the brain and heart tissues are much more vulnerable to the hypoxic state. ${ }^{24}$ Secondly, nitric oxide (NO) and nitrogen dioxide $\left(\mathrm{NO}_{2}\right)$, also known as the most harmful NOx with respect to human health, are referred to as two major NOx associated with combustion. As NOx are low water-soluble irritants, they thus do not produce the mucous membrane irritation upon the deposition in the upper airways, and recipients may be unaware of ongoing exposure with little or even no warning symptoms. A few early signs consist of mild cough or nausea. Prolonged exposure may allow higher cumulative concentrations of NOx to penetrate deeper into the lower airways, resulting in delayed-onset respiratory problems. In cases of severe acute exposure, patients may present with shortness of breath, cough, or symptoms consistent with acute respiratory distress syndrome. Exceptionally, eye irritation may occur following accidental contact between the eyes or associated membranes with relatively high $\mathrm{NO}_{2}$ concentrations. ${ }^{25}$ In general, around $90-95 \%$ of NOx are emitted as NO and 5$10 \%$ as $\mathrm{NO}_{2}$ during combustion. However, $\mathrm{NO}$ is then rapidly oxidized into $\mathrm{NO}_{2}$ in the ambient conditions, and this oxidization is slower under the indoor settings. Thus, $\mathrm{NO}_{2}$ levels can be considered as standard values for $\mathrm{NOx}$ in certain scenarios. The measurements of $\mathrm{NO}_{2}$ emitted 
from incense burning in two shrines in Chiang Mai, Thailand showed that the concentrations were significantly higher on special occasions than during normal periods due to the increased amount of incense burned. Nevertheless, the $\mathrm{NO}_{2}$ levels did not exceed the HKIAQO 8 h-average good class concentration of $\mathrm{NO}_{2}$ $(<0.080 \mathrm{ppm}),{ }^{26}$ as comparable as data in previous study. ${ }^{18}$ In contrast, the peak concentrations for NOx emitted from two different types of Arabian incense were recorded as high as from 0.1 to $0.3 \mathrm{ppm}$. Furthermore, NOx levels were observed with a time-weighted average of 150-200 $\mathrm{ppb} / \mathrm{h}$ that were not only greater than previous data from environmental tobacco smoke but also over the government regulation values in United Arab Emirates. ${ }^{11}$ This may be due to the distinguishing feature that Arabian incense requires charcoal briquettes as combustion aid, as opposed to other self-burning forms commonly used around the world. Finally, it was reported that $\mathrm{SO}_{2}$ emission rate was of $25.5 \mathrm{mg} / \mathrm{h}$ from a cone of incense burned in a $30-\mathrm{m}^{3}$ environmental chamber for $38 \mathrm{~min}$, and estimated peak concentration was of $0.45 \mathrm{mg} / \mathrm{m}^{3}$. In comparison to the outdoor concentrations stated in US EPA NAAQS for $\mathrm{SO}_{2}$ are of $1.3 \mathrm{mg} / \mathrm{m}^{3}, 0.365 \mathrm{mg} / \mathrm{m}^{3}$, and $0.080 \mathrm{mg} / \mathrm{m}^{3}$ for a(n) 3-h average, 24-h average, and annual arithmetic mean, respectively, $\mathrm{SO}_{2}$ concentrations emitted from incense burning could surpass the standards under certain conditions. ${ }^{2}$ Several reviews regarding the health effects of acute and chronic low- or high-dose $\mathrm{SO}_{2}$ exposure on humans and animals have been published during recent years. Briefly, $\mathrm{SO}_{2}$ has been not only documented as a respiratory irritant and bronchial constrictor but also associated with cardiovascular conditions, leading to the increased admissions, morbidity and mortality with respect to cardiopulmonary issues. ${ }^{27}$

\section{Particulate Matter}

Particulate matter (PM) is referred to all the dust, smoke, and haze particles suspended in the ambience. In the other words, PM can be described as a complex mixture of physically and chemically diverse particles as solids and/ or liquid droplets suspended in the atmosphere. ${ }^{28}$ The major sources of PM result from human life, particularly combustion-related activities. Given incense burning is a slow and incomplete combustion process, the burning process of incense is able to produce significant quantities of PM. Indeed, an investigation conducted in a temple in central Taiwan found that the concentrations of different PM fractions were significantly increased during heavy incense burning episodes, ${ }^{29}$ consistent with other studies. ${ }^{30-32}$ Likewise, incense burning in the indoor settings was found to generate an average of greater than $45 \mathrm{mg}$ of PM per gram of incense burned, as opposed to approximately $10 \mathrm{mg} / \mathrm{g}$ for the cigarette. ${ }^{33}$ Similarly, the characterization of PM emissions from incense burning reported that emission rates and emission factors of the $\mathrm{PM}$ fine fraction ranged from 7 to $202 \mathrm{mg} / \mathrm{h}$ and from 5 to $56 \mathrm{mg} / \mathrm{g}$ of incense burned, respectively. ${ }^{2}$ Notably, the levels of PM emitted from 10 common types of incense manufactured in different regions were found to significantly surpass the HKIAQO regardless of the type of incense. ${ }^{18}$ From the viewpoint of health effects, PM can be categorized according to its aerodynamic diameter, since the smaller the particles are, the deeper they can penetrate and the more damage they might cause. There are typically two basic particle metrics of PM, a so-called coarse fraction and a fine fraction. In addition, the smallest particles identified up to date are termed ultrafine particles that are generally lesser than a few hundred nanometers. ${ }^{34}$ Compelling evidences have reported the association between exposure to these particles, especially fine and ultrafine fractions, with increased hospital admission, morbidity, and mortality, mainly due to respiratory problems and cardiovascular diseases. ${ }^{28,35}$ Remarkably, the specialized cancer agency of World Health Organization (WHO) namely International Agency for Research on Cancer (IARC) has stated that exposure to PM causes lung cancer, leading to its classification as carcinogenic to humans since $2013 .^{36}$ So far, a growing body of studies has also demonstrated the positive correlation between the increasing level of exposure to PM with the increasing risk of cancers of other sites, which was summarized in our recent work. ${ }^{37}$

\section{Organic Compounds}

The fragrance material presenting in the incense is generally originated from plant extracts. Many types of fragrant woods, resins, herbs, and essential oils can be used alone or together to provide the aroma to the incense products which generates the fragrant smoke when the incense is burned. ${ }^{16}$ As this major constituent is composed of organic matters, incense typically gets volatilized during its combustion. ${ }^{20}$ In fact, a wide range of toxic organic compounds has been identified in the incense smoke, among which carbonyls, volatile organic compounds (VOCs), and polycyclic aromatic hydrocarbons (PAHs) have been commonly reported. The emissions of carbonyls from the 
burning of ten different incense types in a large environmental test chamber detected a total of eight carbonyl compounds, predominantly aldehydes. Remarkably, the formaldehyde concentrations of six types were higher than the 8-h average formaldehyde concentration recommended by HKIAQO $\left(100 \mu \mathrm{g} / \mathrm{m}^{3}\right)$, and the highest burning level of formaldehyde even surpassed the standard value by twice. ${ }^{18}$ Likewise, previous study that collected air samples from a home and a temple in Hong Kong where incense burning had occurred on a daily basis also detected a significant emission of carbonyls with formaldehyde as the most abundant carbonyl compound. In addition, the total mixing ratios of the carbonyls were higher inside the temple than outside the temple by 11-23 times, and the formaldehyde concentrations in both places were measured to exceed the WHO air quality guideline. ${ }^{38}$ Regarding VOCs, their emission from incense burning at different temples in China were measured and analyzed as well. The results found that there were twelve kinds of VOCs identified in the air samples, among which benzene, toluene, and xylene were the abundant species whose concentrations surpassed the recommended levels of $0.05 \mathrm{mg} / \mathrm{m}^{3}$ by WHO. ${ }^{39}$ Similarly, the identification and quantification of VOCs in the gaseous phase from the burning of three incense types detected from 14 to 17 kinds of VOCs in incense smoke, where benzene followed by toluene were the major VOCs emitted during incense smoldering in aspects of emission rate and emission factor regardless the incense type. ${ }^{40}$ Recent data regarding the emission from burning of nine incense products in a specific room of experimental house dedicated to indoor air research also observed VOCs, including benzene and toluene, at highly significant concentrations. ${ }^{41}$ Besides, there might be a wide variety of PAHs found in the incense smoke such as naphthalene, acenaphthene, acenaphthylene, fluorene, phenanthrene, anthracene, fluoranthene, pyrene, chrysene, benzo[a]anthracene, benzo[b]fluoranthene, and benzo[a]pyrene. It was indicated that the total mean concentration of PAHs in the Arabian incense samples was $2.79 \mathrm{mg} / \mathrm{m}^{3}$, greater than the recommendation levels given by different environmental agencies. ${ }^{42}$ In another study in Taiwan, the mean total-PAH concentrations in the indoor air inside the temple was $6258 \mathrm{ng} / \mathrm{m}^{3}$, approximately 27 times higher than that found outside the temple and 11.6 times greater than that at the urban site. This measurement also reached nearly $80 \%$ of the concentration at the traffic source, indicating the high PAH concentrations inside the temple. While around $90 \%$ of the indoor airborne PAHs detected in the temple were in the gaseous phase, the mean value of particle-bound $\mathrm{PAH}$ concentrations inside the temple was twice and 1.2 times as high as that found outside the temple and at the urban site, respectively. ${ }^{43}$ Consistently, significant amounts of PAHs released into the ambience during the incense burning were reported in other investigations. ${ }^{44,45}$ Importantly, it was observed that the PAHs concentrations of incenseburning homes were higher than those found in nonincense-burning homes, and the indoor levels of PAHs were significantly greater than the outdoor concentrations. $^{43}$ Collectively, incense smoke contains considerable concentrations of multiple organic compounds that present in gaseous phase and can be absorbed into PM particles. Among the compounds, formaldehyde, benzene, toluene, and a mixture of PAHs have aroused the concerns of researchers not only for their high levels but also for their detrimental effects on human health and the whole environment. Notably, these compounds have been well-established as human carcinogens by IARC. ${ }^{46}$ In addition to carcinogenicity, short-term and long-term exposure to such toxicants might result in a series of adverse effects from mild to severe such as eye, nose, throat or skin irritation, narcosis, neurotoxicity, aplastic anaemia, cardiovascular conditions, respiratory problems, and kidney or liver damage, among others. ${ }^{47-49}$

To sum up, chemicals produced by incense burning can be divided into two categories: particulate phase and gaseous phase, that are emitted simultaneously. Due to the variations of incense composition and experimental design, the characterization of incense smoke that has been reported remains highly variable, as presented in Table 1 .

\section{Evidence-Based Associations Between Incense Burning and Health Effects}

Considering incense smoke is a complex mixture of suspended particulates and harmful gases, the identification of adverse effects associated with incense smoke on human health has captured the concerns of scholars from multiple disciplines all over the world. To date, associations between incense burning and an array of conditions have been suggested (Figure 1). However, findings regarding this issue remain elusive, demanding further investigations. 
Table I Summary of Emission Characterization from Incense Burning

\begin{tabular}{|c|c|c|c|c|c|c|c|c|}
\hline Study Design & co & NOx & $\mathrm{SO}_{2}$ & PM & Carbonyls & vocs & PAHs & Ref \\
\hline \multicolumn{9}{|c|}{ Peak concentration $\left(\mathrm{mg} / \mathrm{m}^{3}\right)$} \\
\hline 02 Types of Arabian incense; $22 \mathrm{~m}^{3}$ test chamber & 122.1 ppm & $0.3 \mathrm{ppm}$ & $-/-$ & 1.42 & $85.2 \mathrm{ppb}$ & $-/-$ & $-/-$ & 11 \\
\hline 10 Types of different incense kinds; $18.26 \mathrm{~m}^{3}$ test chamber & 38.77 ppm & $0.427 \mathrm{ppm}$ & $-1-$ & $\begin{array}{l}38.351^{\mathrm{c}} \\
46.285^{\mathrm{d}}\end{array}$ & $-1-$ & $\begin{array}{l}0.117^{f} \\
0.096^{8}\end{array}$ & $-1-$ & 18 \\
\hline Air sampling at 2 shrines, Thailand & $-/-$ & $0.075^{\mathrm{b}} \mathrm{ppm}$ & $-1-$ & $0.764^{\mathrm{c}}$ & $-/-$ & $-/-$ & $-/$ & 26 \\
\hline Air sampling at temple, central Taiwan & $-/-$ & $-1-$ & $-/-$ & $\begin{array}{l}0.181^{\mathrm{c}} \\
0.253^{\mathrm{d}}\end{array}$ & $-/$ & $-/-$ & $-1-$ & 29 \\
\hline Air sampling at temple, central Taiwan & $-1-$ & $-/$ & $-1-$ & $\begin{array}{l}0.108^{\mathrm{c}} \\
0.151^{\mathrm{d}}\end{array}$ & $-/$ & $-1-$ & $-1-$ & 30 \\
\hline Air sampling at 2 temples, central Taiwan & $-/-$ & $-/-$ & $-/-$ & $\begin{array}{l}0.444^{\mathrm{c}} \\
0.583^{\mathrm{d}}\end{array}$ & $-/$ & $-/-$ & $-/-$ & 31 \\
\hline Air sampling at temple, central Taiwan & $-1-$ & $-1-$ & $-1-$ & $\begin{array}{l}200.0^{\mathrm{c}} \\
219.7^{\mathrm{d}}\end{array}$ & $-/-$ & $-1-$ & $-1-$ & 32 \\
\hline 03 Types of stick incense; $4 \mathrm{~m}^{3}$ clean room & 71.5 & 2.8 & $-1-$ & 36.6 & $-/$ & $-/-$ & $-/$ & 33 \\
\hline Air sampling at a home and a temple, Hong Kong & $-/-$ & $-/-$ & $-/-$ & $-1-$ & $\begin{array}{l}678 \mathrm{ppb} \text { (temple) } \\
179.2 \mathrm{ppb} \text { (home) }\end{array}$ & $-/-$ & $-1-$ & 38 \\
\hline Air sampling at 3 temples, China & $-/$ & $-/-$ & $-1-$ & $-/$ & $0.97^{\mathrm{e}}$ & 2.72 & $-/-$ & 39 \\
\hline 03 Types of different incense kinds; incense combustion system & $-1-$ & $-/-$ & $-/-$ & $-1-$ & $-/$ & 18.474 & $-/-$ & 40 \\
\hline Oud incense; test chamber & $-1-$ & $-/$ & $-/-$ & - & $-/-$ & $-/$ & 5.72 & 42 \\
\hline Air sampling at temple, southern Taiwan & $-/$ & $-/$ & $-1-$ & 0.188 & - & $-/$ & 0.009 & 43 \\
\hline Incense joss stick; $78.3 \mathrm{~m}^{3}$ room under 2 conditions & $-1-$ & $-/-$ & $-1-$ & $0.723^{\mathrm{d}}$ & $-/$ & $-/-$ & 0.0005 & 44 \\
\hline Air sampling at temple, Thailand & $-1-$ & $-/$ & $-1-$ & $0.406^{\mathrm{c}}$ & $-/$ & $-/-$ & 0.00005 & 45 \\
\hline \multicolumn{9}{|c|}{ Emission rate $(\mathrm{mg} / \mathrm{min})$} \\
\hline 23 Types of different incense kinds; $30 \mathrm{~m}^{3}$ test chamber & 8.85 & $0.073^{\mathrm{a}}$ & 0.425 & $\begin{array}{l}3.367^{\mathrm{c}} \\
3.350^{\mathrm{d}}\end{array}$ & $-1-$ & $-1-$ & $-1-$ & 2 \\
\hline 02 Types of Arabian incense; $22 \mathrm{~m}^{3}$ test chamber & $23.1-67.6$ & $0.094-0.134$ & $-1-$ & 5.9 & 0.028 & $-/-$ & $-/-$ & 11 \\
\hline 10 Types of different incense kinds; $18.26 \mathrm{~m}^{3}$ test chamber & 13.245 & 0.163 & $-1-$ & $\begin{array}{l}36.005^{\mathrm{c}} \\
42.277^{\mathrm{d}}\end{array}$ & $-1-$ & $-1-$ & $-1-$ & 18 \\
\hline 03 Types of different incense kinds; incense combustion system & $-1-$ & $-/$ & $-1-$ & $-1-$ & $-/$ & $\begin{array}{l}0.050^{f} \\
0.041^{g}\end{array}$ & $-1-$ & 40 \\
\hline \multicolumn{9}{|c|}{ Emission factor (mg/g incense burned) } \\
\hline 23 Types of different incense kinds; $30 \mathrm{~m}^{3}$ test chamber & $-/-$ & $-1-$ & $-1-$ & $\begin{array}{l}55.7^{\mathrm{c}} \\
59.4^{\mathrm{d}}\end{array}$ & $-1-$ & $-/-$ & $-1-$ & 2 \\
\hline 02 Types of Arabian incense; $22 \mathrm{~m}^{3}$ test chamber & $331.7-509.3$ & $1.5-2.2$ & $-1-$ & $174.7-187.0$ & 12.3 & $-1-$ & $-1-$ & 11 \\
\hline $\begin{array}{l}\text { 10 Types of different incense kinds; } \\
18.26 \mathrm{~m}^{3} \text { test chamber }\end{array}$ & 277.7 & 3.3 & $-1-$ & $\begin{array}{l}205.4^{\mathrm{c}} \\
241.2^{\mathrm{d}}\end{array}$ & $-/-$ & $\begin{array}{l}1.786^{f} \\
0.707^{8}\end{array}$ & $-1-$ & 18 \\
\hline Indian musk incense stick; test chamber under 4 conditions & $110-120$ & $-/-$ & $-/-$ & $\begin{array}{l}2.5-3.0^{\mathrm{c}} \\
32-33^{\mathrm{d}}\end{array}$ & $-/-$ & $-1-$ & $-/-$ & 22 \\
\hline 03 Types of stick incense; $4 \mathrm{~m}^{3}$ clean room & $-1-$ & $-1-$ & - & 45.6 & - & $-/$ & - & 33 \\
\hline $\begin{array}{l}03 \text { Types of different incense kinds; } \\
\text { incense combustion system }\end{array}$ & $-1-$ & $-1-$ & $-1-$ & $-1-$ & $-/$ & $\begin{array}{l}1.771^{f} \\
1.482^{g}\end{array}$ & $-/$ & 40 \\
\hline
\end{tabular}

Notes: The data displayed in the table are the highest values measured in each study. -/- not measured; ${ }^{\mathrm{a}} \mathrm{NO} ;{ }^{\mathrm{b}} \mathrm{NO}{ }_{2} ;{ }^{\mathrm{C} P M} 2.5 ;{ }^{\mathrm{d}} \mathrm{PMI} 0$; ${ }^{\mathrm{e}}$ formaldehyde; ${ }^{\mathrm{f}}$ benzene; ${ }^{\mathrm{g}}$ toluene. 


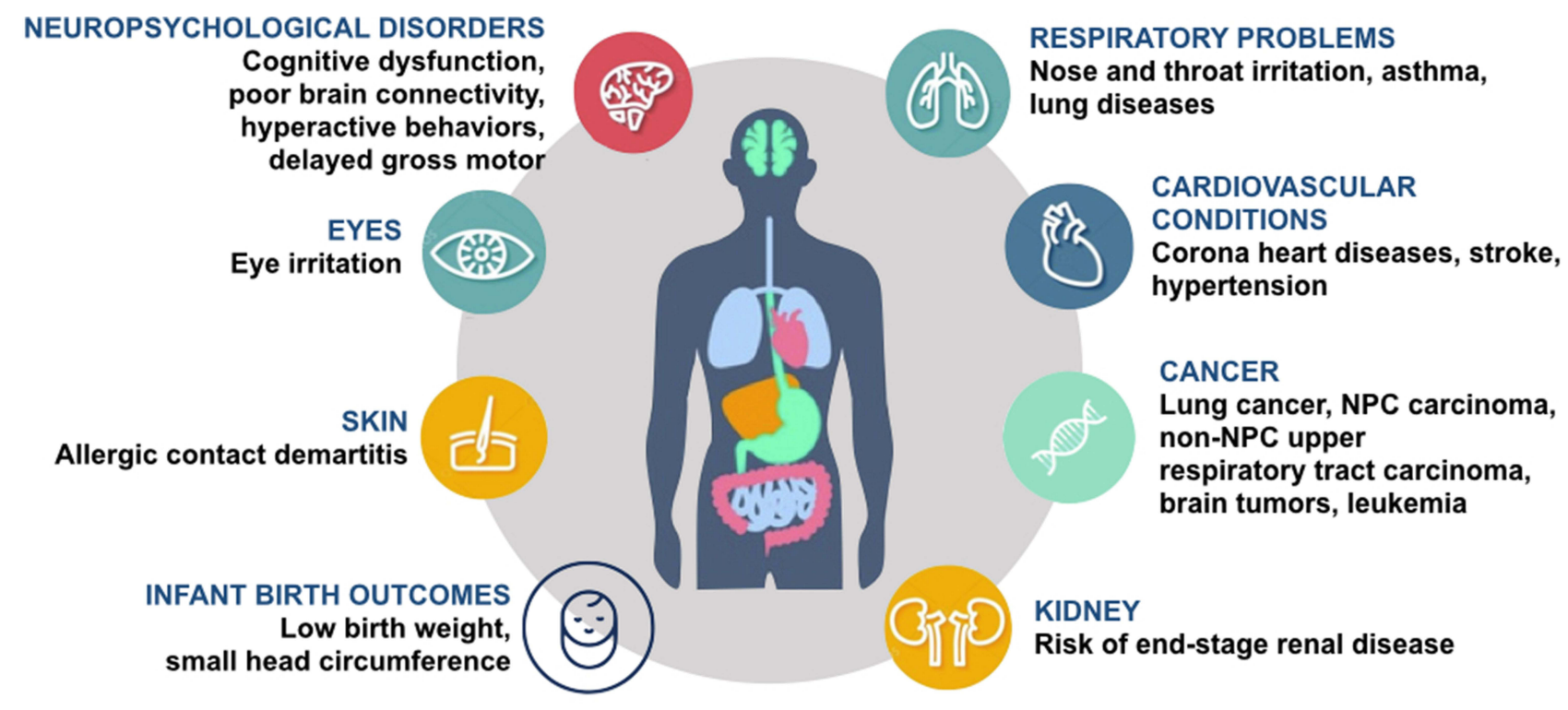

Figure I Possible adverse effects of incense smoke on human health. Individuals who expose to incense burning may inhale a complex mixture of deleterious chemicals, resulting in a wide variety of conditions ranging from irritation to cancer. The potential impact of incense burning has been observed in many vital organs.

\section{Irritation}

Since incense smoke contains a number of irritants, it is possible to result in several irritative responses, including allergic reactions, in many parts of body such as eyes, nose, throat or skin. In fact, a series of clinical case reports have indicated that incense smoke can cause allergic contact dermatitis in various sites of the human body. For instance, a 63-year-old man who had practiced the incense burning for about 15 years was presented with itchy depigmented macules on his left dorsum manus, left shoulder and abdomen, and the perfume in the incense was identified as the culprit. ${ }^{50}$ Another case was that a woman who had burned incense every day for approximately 5 years developed airborne pigmented contact dermatitis due to musk ambrette in incense. ${ }^{51}$ On the other hand, the prevalence of acute irritative symptoms was cross-sectionally investigated among a group of temple workers in Kao-Hsiung, Taiwan, in comparison to a group of church workers. The results showed that a set of acute adverse symptoms including irritation of the eyes, nasal secretions, dryness or congestion, irritation or dryness of the throat, and nausea was evidently more prevalent among temple workers than church workers. Moreover, as observed in the models controlled for potential confounders, working in temples seemed to relate to $45 \%$ and $41.4 \%$ greater chance of acquiring throat irritation and nose irritation, respectively, as compared to working in churches, suggesting the association between occupational exposure to incense burning and the increased risk for the development of acute irritation. ${ }^{52}$ Similarly, in another cross-sectional population-based study that consisted of a total of 36,541 adults from 6 big cities across China, around $15.1 \%$ of the homes had burned incense, and incense burning was associated with weekly symptoms of eyes (itching, burning or irritation of the eyes), throat (hoarse or dry throat), and skin (dry or flushed facial skin, scaling/itching skin in scalp or ears, dermal symptoms in hands such as dry, itching or red skin). ${ }^{53}$ Importantly, according to a Taiwanese birth cohort, regular incense burning was the most critical risk factor among housing characteristics on health status of children from 3 to 5 years old regardless of parental history of allergic and respiratory diseases. In particular, regular incense burning was found to associate with diagnosed childhood asthma and allergy, and the level of significance was double in the presence of paternal heredity. ${ }^{54}$ Altogether, current literature has favored the clues concerning the association between the exposure to incense burning and the development of irritative and/or allergic symptoms in ages.

\section{Respiratory Problems}

Smoke, regardless of sources, is well-believed to exert deleterious effects on the respiratory system upon inhalation. Thus, when the incense is burned, the emitted smoke is likely to be inhaled into the body, possibly resulting in respiratory problems. In fact, multiple epidemiological studies have indicated 
the effects of incense burning on the respiratory system. However, the results remain elusive. In a prospective cohort study among more than 4000 school children in Hong Kong from 2012 to 2014, the adverse effects of incense burning on lung function and lung function development of children were evidenced. Moreover, exposure to domestic incense burning was found to associate with the increased risks of bronchitis and bronchiolitis in both sexes, and so were pneumonia and wheeze but only in boys. The reasons for such gender sensitivity were unknown. One plausible explanation was that respiratory problems were more prevalent in boys than in girls at the baseline. ${ }^{55}$ Consistently, previous cross-sectional population-based studies among children also indicated that incense burning was associated to the increased risk of various respiratory diseases and symptoms such as asthma, cough, and wheeze in an exposure-response manner. ${ }^{56-58}$ On the other hand, the opposite finding, that is, there was no significant relationship between incense burning with prevalence of respiratory problems including chronic cough, chronic sputum, chronic bronchitis, runny nose, wheezing, asthma, allergic rhinitis or pneumonia was reported in a cross-sectional investigation among 346 primary school children in Hong Kong. ${ }^{59}$ The lack of such association may be due to several reasons. Firstly, the personal exposure to household incense smoke may be relatively low in terms of concentration and duration. Secondly, the competitive effects of other air pollutants may neglect the impact of incense smoke on respiratory system. Finally, the high rates of respiratory diseases and their etiological factors in reality may overshadow the effects of incense smoke. Likewise, the association between exposure to incense smoke and respiratory problems among adolescents and adults have also been documented with inconsistent results. Based on the data from asthma-screening program for adolescents in Taiwan, over 5000 students of 14-16 years of age were recruited, and around $71 \%$ of them were likely to expose to incense burning at home. Approximately $10 \%$ of participated students were randomly selected for lung function examination. As analyzed by multivariable linear regression analysis with controlling of potential confounders, lung functions were significant decreased among students with daily exposure to domestic incense burning as compared to those living in households without incense burning. Besides, there was no significant association between lung function impairment and exposure to incense burning twice a month. ${ }^{12}$ In addition, a cross-sectional health survey among 109 temple workers (as exposure group) and 118 church workers (as control group) in Kao-Hsiung, Taiwan showed that chronic respiratory symptoms including cough, phlegm, wheezing or dyspnea were more common among temple workers than church workers. In particular, the rates of cough, phlegm, and dyspnea were evidently higher in exposure group. Remarkably, cough symptoms remained significantly more prevalent in temple workers after potential confounders controlling, suggesting that exposure to incense smoke may increase the risk for the development of respiratory symptoms. ${ }^{52}$ In contrast, the lack of significant association between incense burning and increased respiratory problems in adults was reported as well. ${ }^{59}$ Furthermore, a Taiwanese cohort study indicated that shortterm exposure to incense burning may not influence lung function and respiratory symptoms in patients with chronic obstructive pulmonary disease (COPD), which is an incurable disease characterized by chronic airflow blockage and worsening lung function. ${ }^{60}$ Similarly, previous case-control study in Saudi Arabia also did not found the use of incense burners as a risk factor of COPD. ${ }^{61}$ However, the small sample sizes and non-longitudinal study design may have influenced the results and may not be generalizable to the COPD population. Experimentally, evidences attained from animal studies have linked incense burning with adverse ultrastructural pulmonary changes. ${ }^{62,63}$ For instance, rats were exposed to a type of Arabian incense for 14 weeks at the rate of 4 grams/day in the exposure chamber exhibited evident ultrastructural changes in alveolar pneumocytes of exposed animals as compared to those of non-exposed controls. Such alterations included alveolar cell hyperplasia and subsequent alveolar septal hypercellularity, neutrophil cell infiltration in the alveolar lumena, degenerative and necrotic changes of alveolar lining cells, erythrocyte extravasation from the distended alveolar capillaries, and collagen fibril deposition and subsequent alveolar walls thickening. ${ }^{62}$ Taken together, existing evidences have indicated the potential linkage between the exposure to incense burning and the development of various respiratory problems. However, the findings remain inconsistent due to the variations regarding concentration, frequency, and duration of exposure among different populations, requiring further investigations.

\section{Cardiovascular Conditions}

Numerous epidemiological and biomedical studies have indicated the ability of incense smoke to induce various cardiovascular conditions. Importantly, the strong relationship between incense use and death due to cardiovascular diseases (CVDs) was reported. ${ }^{13} \mathrm{~A}$ cross-sectional study conducted among 132 Thai-Vietnamese adults aged more than 35 years in Thailand demonstrated the positive association between household incense burning and carotid artery intima-media thickness (CIMT) in multivariable 
regression analysis after controlling potential confounding factors. ${ }^{64}$ Since CIMT generally identifies the levels of atherosclerosis and thus estimates the risk of CVDs, ${ }^{65}$ such findings suggest that incense burning at home may be a risk factor for the development of cardiovascular conditions. In addition, through an analysis among 50 housewives living in 50 homes in the Taipei metropolitan area, it was showed that $48 \%$ of homes had practiced incense burning, and incense burning could increase the indoor levels of PM2.5, thus modify the association between household PM2.5 and heart rate variability indices. ${ }^{66}$ This effect modification may also link incense burning to the increased risk of CVDs. Notably, in a large population-based cohort of middle-aged and elderly Chinese in Singapore, chronic exposure to daily incense burning at home for over 20 years was found to associate with the increased risk of cardiovascular mortality. In particular, current incense users may have a $12 \%$ increased risk of cardiovascular mortality, including a $10 \%$ and $19 \%$ increased risk for coronary heart diseases and stroke, respectively, as compared to former and never users. Furthermore, up to $7 \%$ of coronary heart disease deaths and $12 \%$ of stroke deaths in this study population could be attributed to long-term incense use. ${ }^{13}$ Although some limitations still remained in the study, such cohort investigation provided strong evidence regarding the causal relationship in which the exposure of incense smoke preceded the cardiovascular mortality as health outcome. In line with epidemiological investigations, an experimental study on rats found that exposure to incense smoke was associated with adverse metabolic changes of increased triglycerides and decreased high-density lipoprotein cholesterol concentrations over time. ${ }^{67}$ Another animal experiment also observed that incense smoke-exposed rats exhibited pronounced ultrastructural changes in heart muscle tissue, cardiac hypertrophy which correlated with the increased hypertrophic gene expression, and cardiac tissue damages characterized by significant elevation of creatine kinase-myocardial bound and lactate dehydrogenase. ${ }^{68}$ The endothelial function was investigated by flowmediated dilation in pigs, and the significant impairment of flow-mediated dilation was observed following a 30min exposure to incense smoke. Interestingly, such impairment was well correlated with $\mathrm{CO}$ levels in the exposure chamber but neither total particulates nor venous COhemoglobin, implying that the gaseous phase of incense smoke that accompanied $\mathrm{CO}$ rather than $\mathrm{CO}$ itself was responsible for acute endothelial dysfunction upon exposure to incense smoke. ${ }^{69}$ Similarly, the relationship between endothelial dysfunction with temple particles was demonstrated through the findings that exposure of human coronary artery endothelial cells to particles collected at a major Chinese temple led to the remarkably increased endothelin- 1 and decreased nitric oxide synthesis. ${ }^{70}$ While the underlying mechanisms remain unclear, those experimental evidences have supported the concern about the increased CVD risk in individuals exposed to incense smoke. On the other hand, as a major risk factor for CVDs, the association between incense burning and hypertension was investigated. Based on the data from a crosssectional survey in China, a population-based study was conducted, and a significant association between the frequency of incense burning with the risk of hypertension and the increase of blood pressure was observed with a clear exposure-response relationship. Subsequent gender-specific analyses indicated that larger effects were found among women than men. ${ }^{71}$ This could be due to the fact that Chinese women spend more time at home and engage in more ritual activities than men do, leading to higher personal exposure to incense smoke. Similarly, the association between frequent exposure to household incense burning with higher risk of hypertensive disorder and higher levels of blood pressure was also demonstrated in a large Chinese birth cohort study but among pregnant population. ${ }^{72}$ Collectively, incense burning should be considered as a risk factor for a variety of adverse cardiovascular outcomes and associated conditions, with frequency and duration may be important determinants.

\section{Neuropsychological Disorders}

A few pieces of current evidence have indicated a plausible linkage between incense burning and several neuropsychological disorders. In a 3-year prospective longitudinal casecontrol study among 515 stroke- and dementia-free adults aged $\geq 65$ years in Hong Kong, incense users were found to associate with poorer cognitive performance and decreased brain connectivity as compared to non-users. Moreover, significant interactions were observed between indoor incense burning with diabetes mellitus, hyperlipidemia and white matter hyperintensities, predisposing poorer cognitive functions caused by incense burning in the presence of vascular risk factors. ${ }^{73}$ Notably, exposure to incense burning during pregnancy may have profound neural effects in offspring. According to a Chinese cohort study comprising nearly 43,000 participants, it was calculated that prenatal exposure to incense burning was significantly and positively associated 
with early-onset hyperactive behaviors in preschoolers. ${ }^{74}$ Similarly, by using nationwide data set from Taiwan Birth Cohort Study, delayed gross motor milestone achievement was found among infants born in homes with incense burning. Remarkably, the association was more apparent in motherinfant pairs under persistent exposure category, suggesting a possible dose-response effect. ${ }^{75}$ Also based on Taiwan Birth Cohort Study, the negative relationship between prenatal incense burning with infant birth outcomes as measured by birth weight and head circumference was established in another investigation. In particular, incense was found to associate with lower birth weight in boys but not in girls, and so was smaller head circumference. ${ }^{76}$ The poor infant health at birth has been documented to associate with higher risk of neurodevelopmental abnormalities. ${ }^{77,78}$ Therefore, despite the paucity of published data, the potential adverse effects of personal and maternal exposure to incense burning on neuropsychological development and function should not be overlooked.

\section{Cancers}

Experimentally, incense smoke has been demonstrated to be mutagenic and/or genotoxic by different assays in earlier in vitro studies, ${ }^{79-81}$ possibly resulting in DNA adduct generation which is a pivotal step in the process of carcinogenesis. In fact, incense burning can emit large amounts of toxicants, many of which are recognized or suspected as human carcinogens, particularly associated with lung cancer. So far, the association between incense burning and lung cancer remains a contentious issue. One of the earliest evidences for positive association was a hospitalbased case-control study in Singapore in 1970s, where univariate analysis reported a strong relationship between lung cancer and incense use while sleeping with overall relative risk of $4.11(\mathrm{p}<0.01){ }^{82}$ The lack of adjustment of potential confounders such as age, gender, and smoking status was a major drawback of that study. Following the adjustment for smoking and confounding demographic variables, another hospital-based case-control investigation with 331 lung cancer cases and 331 matched controls in Hong Kong indicated that exposure to incense burning during festivals was associated with a significantly higher risk of lung cancer among women (adjusted Odd ratio $(\mathrm{OR})=2.95 ; 95 \%$ confidence interval $(\mathrm{CI}): 1.10-7.87)$ but not daily exposure (adjusted OR $=1.58 ; 95 \% \mathrm{CI}$ : 0.77-3.26). Meanwhile, neither daily exposure (adjusted $\mathrm{OR}=0.94 ; 95 \%$ CI: 0.56-1.56) nor festival (adjusted OR $=1.03 ; 95 \%$ CI: $0.47-2.26$ ) showed an association with the increased risk of lung cancer among men. ${ }^{83}$ The stronger association found among women might be due to their higher tendency of incense use. However, in a Chinese population-based case-referent study with 1208 male lung cancer cases and 1069 matched referents, the unconditional multivariable logistic regression analysis demonstrated that lung cancer risk in the whole population was significantly increased among men who had exposed to frequent incense burning ( $\geq 2$ times/day; OR $=1.26 ; 95 \%$ CI: 1.01-1.58) or experienced high cumulative incense exposure $(\geq 60$ day-years; OR $=1.38$; $95 \%$ CI: 1.10 $1.75)$ as compared to those who had never done after potential confounder adjustment. Moreover, synergy index for either smoking and frequent incense use or smoking and high cumulative use both indicated that the joint effect of these exposures on lung cancer risk was as twice much as expected assuming additive effects, suggesting more pronounced association between incense use and lung cancer in male smokers. ${ }^{14}$ Similar interaction between smoking and exposure to incense or mosquito coils $(\mathrm{p}=0.016)$ was reported as well. In particular, ORs for smokers with and without daily use of incense or mosquito coils were 4.61 and 2.80, respectively. ${ }^{84}$ Nonetheless, the combination between daily use of incense and mosquito coils as exposure of interest rather than single incense exposure may misjudge the linkage between incense use and lung cancer risk. On the other hand, the null association between incense use and lung cancer has also been documented. A Singapore Chinese populationbased prospective cohort study was unable to observe the overall effect of incense use on lung carcinoma development regardless the smoking status. ${ }^{15}$ Besides, the impact of incense use on the risk of other respiratory tract cancers other than lung cancer has been commonly investigated as well, and most of existing evidences have been in respect with nasopharyngeal carcinoma (NPC). A case-control study among Hong Kong Chinese with 352 incident cases of NPC and 410 controls observed an increased risk of NPC among women who had burned incense daily at home (adjusted OR $=2.49 ; 95 \%$ CI: $1.33-1.46$ ) but not among men (adjusted OR $=0.96$; 95\% CI: $0.63-$ 1.45). Remarkably, evident exposure-response relationship was found, where the risk for NPC in women who had practiced daily domestic incense burning for 40 years or more was over four times that in non-users. ${ }^{85}$ Similarly, a Chinese large-scale case-control study with 1845 cases and 2275 controls also reported a positive association between incense burning and NPC risk. After adjusting 
for potential confounding factors, frequent incense users had approximately $73 \%$ higher risk of NPC than those who never burn incense. ${ }^{86}$ In contrast, a prospective cohort study of Singapore Chinese was unable to observe the association between current use of incense and the increased risk of NPC. Instead, incense use was found to associate with an increased risk of non-NPC upper respiratory tract carcinoma in dose-dependent manner. ${ }^{15}$ Apart from respiratory tract cancers, the relationship between incense use and other malignancies such as leukemia and brain tumors has also been reported. Through a casecontrol study of children of ages 10 years and under in Los Angeles County, a significant increased risk of leukemia was found among children whose parents had burned incense more than once a week at home during pregnancy or nursing period $(\mathrm{OR}=2.7 ; 95 \% \mathrm{CI}: 1.18-7.14 ; \mathrm{p}=$ 0.007 ), which still remained after adjusting for confounding variables such as parental occupational exposure, parent use of garden sprays, or parent use of household pesticides. ${ }^{87}$ On the other hand, as a source of nitrosamine and other N-nitroso compounds, incense burning has been hypothesized as a risk factor for brain tumors since the early 1980s. A case-control study with 209 young brain tumor patients and 209 controls observed a significant association between maternal exposure to incense during the index pregnancy and the increased risk of brain tumors $(\mathrm{OR}=3.3 ; \mathrm{p}=0.005) .{ }^{88}$ As opposed, such association was not found in other case-control investigations. ${ }^{89,90}$ Although two later studies did not confirm the previous finding, the frequency of case mothers who had burned incense was equivalent or slightly greater than control mothers. Collectively, the possible association between personal or gestational exposure to incense with the increased risk of cancers has been documented albeit it remains controversial. Such conflicting findings may be due to the differences in terms of referent selection, confounder controlling, and sample size. Therefore, larger prospective cohorts in the future with proper referent selection and appropriate adjustment in analyses are highly warranted.

\section{Other Conditions}

Scatter pieces of evidence regarding other adverse effects of incense burning on human health have been documented. In a case report, a 65-year-old female homemaker who had exposed to a large amount of smoke from daily use of incense for over 30 years presented with dizziness, fatigue, severe anemia, pitting edema of the lower legs, sore limbs, abdominal pain, and exertional dyspnea. Remarkably, the blood lead levels of patient and all her family members were as high as lead poisoning. ${ }^{91}$ Besides, a large-scale cross-sectional investigation among Taiwanese preschoolers identified domestic incense burning as a significant factor for the increased blood lead levels ( $p<0.0003$ ), in which a dose-dependent relationship with frequency of incense burning was established $(p=0.0022) .^{92}$ These preliminary findings suggest the greater risk of lead exposure for the families with the custom of incense burning. On the other hand, a recent population-based prospective cohort of middle-aged and older Singapore Chinese found that current users of incense had $23 \%$ higher risk of developing end-stage renal disease as compared to nonusers after adjustment for potential confounders. This risk further increased in cases of daily users with more than 20 years of incense burning. ${ }^{19}$ Consistently, the adverse effects of chronic exposure to incense smoke on kidney function and architecture were observed in previous experimental study. In particular, exposed rats exhibited significantly persistent inflammation as well as abnormal functions and ultrastructural changes of kidney. ${ }^{93}$ Current limited information may send some signals to the researchers for taking further steps in order to build-up a more comprehensive panorama about all possible hazards from incense burning.

\section{The Involvement of Oxidative Stress in Health Effects Associated with Incense Burning}

Oxidation-reduction (redox) homeostasis is vital to life since redox processes involve all fundamental processes from bioenergetics to metabolism to other functions. ${ }^{94}$ The global concept of oxidative stress is "an imbalance between oxidants and antioxidants in favor of the oxidants, leading to a disruption of redox signaling and control and/ or molecular damage". ${ }^{95}$ The field of oxidative stress research has captured the interest of scientific communities in the world since oxidative stress may provide a prominent contribution to the human diseases. ${ }^{96}$ In the context of adverse health effects associated with incense burning, while the underlying mechanisms remain unclear, several lines of evidences have supported the role of oxidative stress as a possible intermediary pathway. This section aims to analyze available evidences that may shed light on this issue. To summarize, the health outcomes associated to incense burning are assumed to be driven 
by oxidative stress, which in turn leads to aberrant inflammation and irreversible DNA impairment (Figure 2). However, there are still many gaps, therefore requiring further investigations to provide more in-depth understanding.

\section{Sources of Reactive Oxygen Species Generation in Response to Exposure to Incense Burning}

Reactive oxygen species (ROS) refer to as a term for a group of derivatives of molecular oxygen, which are produced by redox reactions or electronic excitation. ${ }^{97}$ The successive intermediate steps of oxygen reduction are the formation of superoxide anion radical, hydrogen peroxide, and hydroxyl radical, representing three major ROS of significance. In addition, ground-state molecular oxygen can be electronically excited into singlet molecular oxygen. ${ }^{98}$ A wealth of information has indicated the importance of ROS for the physiology as functional signaling entities. ${ }^{97}$ In contrast to the physiological levels, high concentrations of ROS can yield damages to cellular macromolecules and other cellular consequences, resulting in oxidative stress and associated pathological states. ${ }^{96}$ It is now clear that ROS generation comes from both endogenous and exogenous sources. The former sources generally include mitochondria, peroxisomes, endoplasmic reticulum, and NADPH oxidase complex, while the latter may be the result of cumulative environmental exposure such as smoking, air pollution, chemicals, xenobiotics, and radiation. ${ }^{99}$ Recently, micro- and nano-soot particles, also known as platforms of ROS generation, ${ }^{100,101}$ have been dominantly found in the incense smoke. These particles could exhibit strong

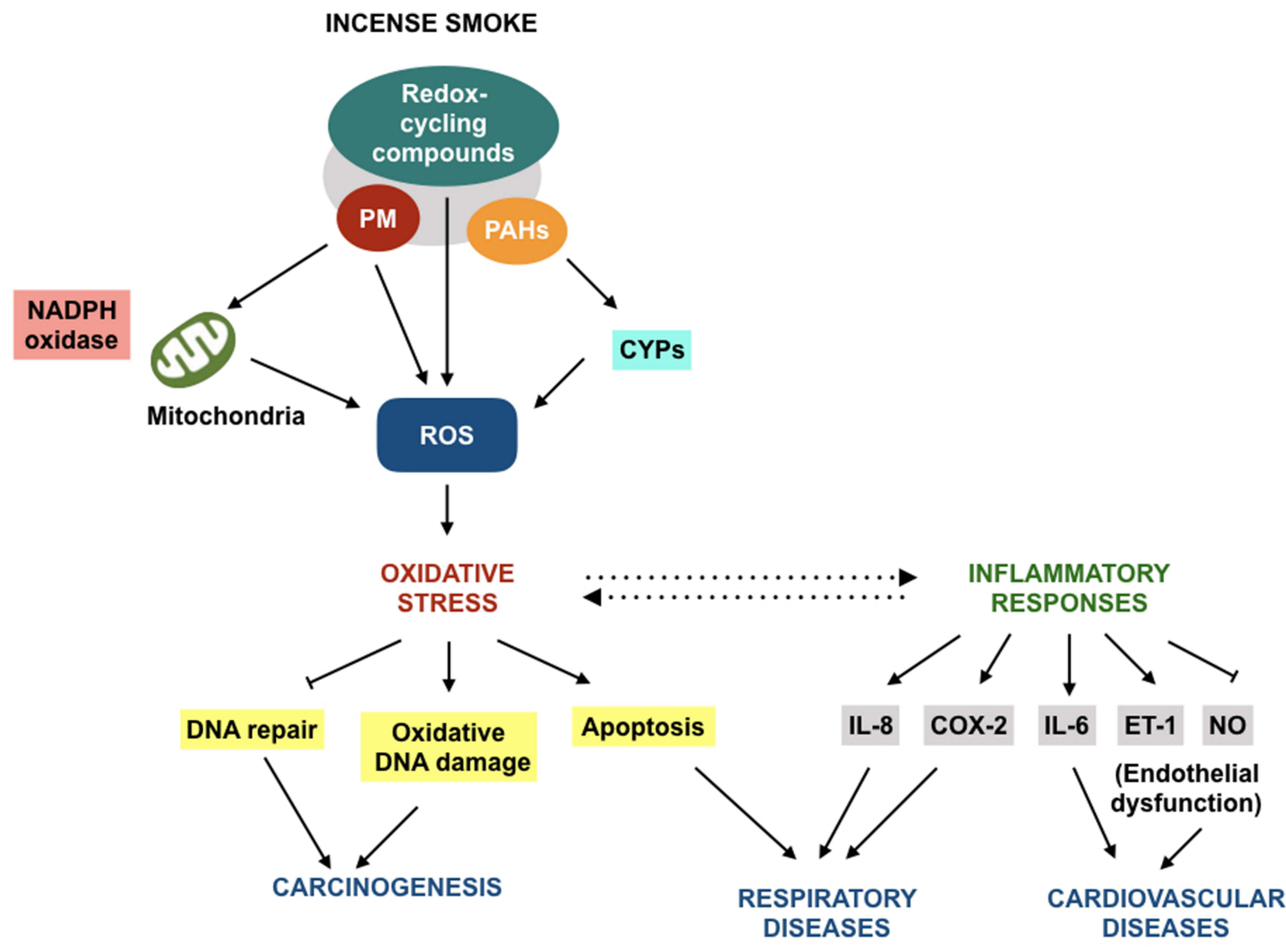

Figure 2 Possible oxidative stress mechanism underpinning the health effects of incense burning. Following the introduction into the body, constituents of incense smoke can enhance ROS generation through some ways, leading to oxidative stress and associated consequences. Carcinogenesis may occur as a result from oxidative DNA damage and improper DNA repair. Besides, oxidative stress and inflammation may be interconnected, contributing to the pathogenesis of cardiopulmonary conditions.

Abbreviations: COX-2, cyclooxygenase-2; CYPs, cytochrome P450 enzymes; ET-I, endothelin-I; IL-6, interleukin-6; IL-8, interleukin-8; NADPH oxidase, nicotinamide adenine dinucleotide phosphate oxidase; NO, nitric oxide; PAHs: polycyclic aromatic hydrocarbons; PM, particulate matter; ROS, reactive oxygen species. 
oxidative capacity with higher ROS generation and greater oxidative DNA damage as compared to both diesel exhaust particles and carbon black. ${ }^{102}$ Also, incense particles were reported to alter the mitochondrial function and NADPH oxidase activity, leading to a second wave of ROS production. ${ }^{102}$ In addition, a broad spectrum of oxygenates including polar organic compounds, highly reactive carbonyls, redox-cycling quinones, and transient metals, among others, have been identified in the whole incense smoke through several investigations. ${ }^{102-104}$ These compounds have been recognized to generate free radicals in biological systems. ${ }^{105-107}$ In fact, incense burning has been reported to trigger Phase I xenobioticmetabolizing enzymes, such as cytochrome P450 (CYP) system which is known for catalytic action for the generation of reactive metabolites from PAHs and other chemicals. ${ }^{68,108,109}$ Altogether, the excessiveness of ROS induced by exposure to incense burning may arise from mixed sources, including (1) incense particles and other oxygenates, (2) mitochondria and NADPH oxidase dysfunctions, and (3) CYP induction. Therefore, incense burning is implicitly the favorable setting for ROS overproduction which possibly in turn mediates the progression to human diseases through oxidative stress.

\section{Oxidative Stress in Response to Exposure to Incense Burning}

The other side of the redox balance is the cellular defenses that counterbalance the deleterious levels of oxidants through enzymatic and nonenzymatic antioxidants, forming an antioxidant network at three fundamental levels of prevention, interception, and repair. ${ }^{97,110}$ The first-line antioxidant defense typically includes three key enzymes: superoxide dismutase (SOD), catalase (CAT), and glutathione peroxidase (GPX), which act to inhibit or prevent the generation of reactive species. ${ }^{111}$ The second line is generally referred to as scavengers that neutralize or scavenge free radicals, among which $\gamma$-L-glutamylL-cysteinyl-glycine, known as glutathione (GSH), is of importance. ${ }^{111,112}$ The third line is a group of enzymes, which repair the damages caused by oxidants to protect the body from their harmful effects. ${ }^{111}$ In this sight, oxidative stress can be considered as a cellular state emerging from the excessive generation of oxidants overwhelming the levels that antioxidant defenses can cope with. ${ }^{113}$ So far, there have been three different lines of evidence reporting the capacity of incense smoke to induce oxidative stress, both in vitro and in vivo, as summarized in Table 2. First, it was reported that incense particles could dose-dependently induce intracellular ROS generation in vitro. ${ }^{114}$ Second, the markedly decreased levels of antioxidants, including SOD, $\mathrm{CAT}$, and GSH, were observed in rats exposed to incense smoke. ${ }^{68,93,109,115}$ Third, the levels of malondialdehyde (MDA), which is a widely used biomarker for oxidative stress assessment, ${ }^{116}$ were significantly increased in response to incense smoke in vivo. ${ }^{68,93,109,115}$ In addition, the expression of heme oxygenase 1 (HO-1), an important marker of oxidative stress, was also induced by incense smoke using cell models. ${ }^{108}$ The findings obtained from existing studies are although useful to suggest the oxidative stress induced by exposure to incense burning, the extrapolation to human remains difficult. Therefore, studies in humans along with the analysis of antioxidant activity/ capacity and/or oxidative stress markers may provide the insights into the actual ability of incense smoke at exposure concentrations to induce oxidative stress.

\section{Oxidative Stress as Underlying Basis of Genetic Toxicities Induced by Incense Smoke}

It is acknowledged that oxidative stress can provoke damages to vital molecules such as proteins, lipids, and nucleic acids. ${ }^{96}$ Literature has reported that DNA may be one of critical targets for ROS induced by incense burning, resulting in oxidative DNA lesions and even impediment of the ensuing transcription, replication, and repair processes. ${ }^{117}$ In fact, temple workers were found to have a twofold increase in the levels of biomarker of oxidative DNA damage namely 8-oxo-2'-deoxyguanosine (8-OHdG) than those of control workers, and so was DNA strand breaks. ${ }^{118}$ Similarly, oxidative DNA damage in human alveolar epithelial A549 cells was also triggered by exposure to PM generated from incense burning, as characterized by the levels of $8-\mathrm{OHdG} .{ }^{117}$ To cope with the consequences of DNA lesions, living beings are equipped with the tools that serve to remove or tolerate DNA damages called DNA repair mechanisms/pathways. ${ }^{119}$ Unfortunately, a significant reduction in DNA repair capacity was observed among temple workers by using cytogenetic challenge assay. ${ }^{118}$ These preliminary data suggest that exposure to incense burning may result in oxidative environment that can threaten the DNA stability. Importantly, the manifestation of oxidative DNA damage along with insufficient DNA repair may be indication for carcinogenesis and other pathologies. $^{120,121}$ 
Table 2 Summary of Evidences About the Capacity of Incense Smoke to Induce Oxidative Stress

\begin{tabular}{|c|c|c|c|}
\hline $\begin{array}{l}\text { Author, } \\
\text { Year }\end{array}$ & $\begin{array}{l}\text { Experimental } \\
\text { Model }\end{array}$ & Experimental Design & Results \\
\hline $\begin{array}{l}\text { Al-Attas } \\
\text { et al, } \\
2015^{68}\end{array}$ & $\begin{array}{l}\text { Male Wistar } \\
\text { Albino rats }\end{array}$ & $\begin{array}{l}\text { Rats were randomly divided into three groups: control, bakhour, } \\
\text { and oudh, with } 24 \text { rats per group. } \\
\text { Rats from bakhour and oudh groups were subjected to the } \\
\text { whole-body smoke exposure in inhalation chambers by burning } 4 \\
g \text { of respective incense on charcoal daily; while control rats were } \\
\text { only exposed to smoke from burning charcoal. } \\
\text { Eight rats from each group were sacrificed after } 30,60 \text {, or } 90 \\
\text { days from the commencement of exposure. }\end{array}$ & $\begin{array}{l}\text { Exposure to incense smoke led to a significant increase in MDA } \\
\text { levels and evident decrease in CAT activity and GSH levels in } \\
\text { heart tissues as compared to the sham-operation. } \\
\text { The levels of oxidative stress markers were comparable among } \\
\text { the studied time points. }\end{array}$ \\
\hline $\begin{array}{l}\text { Chuang } \\
\text { et al, } \\
2013^{114}\end{array}$ & $\begin{array}{l}\text { Alveolar } \\
\text { epithelial A549 } \\
\text { cells }\end{array}$ & $\begin{array}{l}\text { The aqueous stock samples were diluted into four } \\
\text { concentrations by volume, generating } 10 \text { vol\%, } 25 \text { vol\%, } 50 \text { vol\%, } \\
\text { and } 100 \text { vol\% fresh incense PM2.5 suspension. } \\
\text { Cell were incubated with } 10-100 \text { vol\% incense PM } 2.5 \text { suspension } \\
\text { for I h, or with } 10 \text { vol\% incense PM } 2.5 \text { suspension for I, 4, 8, I6, } \\
\text { and } 24 \mathrm{~h} \text {. }\end{array}$ & $\begin{array}{l}\text { Incense PM2.5 induced intracellular ROS generation in } \\
\text { a significant dose-dependent manner. } \\
\text { The increased levels of ROS caused by incense PM } 2.5 \text { were } \\
\text { significantly reduced by the addition of } \mathrm{N} \text {-acetyl cysteine (a } \\
\text { pharmacological antioxidant). }\end{array}$ \\
\hline $\begin{array}{l}\text { Hussain } \\
\text { et al, } \\
2014^{109}\end{array}$ & $\begin{array}{l}\text { Male Wistar } \\
\text { Albino rats }\end{array}$ & $\begin{array}{l}\text { Rats were randomly divided into three groups: control, bakhour, } \\
\text { and oudh, with } 24 \text { rats per group. } \\
\text { Rats in bakhour and oudh groups were subjected to the whole- } \\
\text { body exposure to incense smoke generated from the burning of } \\
4 \mathrm{~g} \text { of respective incense for } 60 \text { min daily in an inhalation } \\
\text { chamber }(72 \times 43 \times 35 \mathrm{~cm}) \text {; while control rats were maintained in } \\
\text { fresh air. } \\
\text { Eight rats from each group were sacrificed after } 30,60 \text {, and } 90 \\
\text { days from the commencement of exposure. }\end{array}$ & $\begin{array}{l}\text { The levels of MDA and GSH were significantly increased in the } \\
\text { lung and liver tissues of rats exposed to incense as compared to } \\
\text { unexposed controls after } 30,60 \text {, or } 90 \text { days. } \\
\text { No statistical difference was found in the lung CAT activity } \\
\text { between exposed and non-exposed rats, but CAT activity was } \\
\text { remarkably altered in the liver tissues of exposed rats after } 60 \\
\text { days as compared to controls. }\end{array}$ \\
\hline $\begin{array}{l}\text { Hussain } \\
\text { et al, } \\
2016^{93}\end{array}$ & $\begin{array}{l}\text { Male Wistar } \\
\text { Albino rats }\end{array}$ & $\begin{array}{l}\text { Rats were randomly divided into three groups: charcoal, } \\
\text { bakhour, and oudh, with } 24 \text { rats per group. } \\
\text { Rats in bakhour and oudh groups were subjected to the whole- } \\
\text { body exposure of incense smoke generated from the burning of } \\
4 \mathrm{~g} \text { of respective incense on self-burning charcoal for } 60 \text { min } \\
\text { daily, while rats in charcoal group were exposed only to } \\
\text { emissions from the burning charcoal. } \\
\text { Eight rats from each group were sacrificed after } 30,60 \text {, and } 90 \\
\text { days from the commencement of exposure. }\end{array}$ & $\begin{array}{l}\text { Rats exposed to incense smoke exhibited remarkable MDA } \\
\text { increase and apparent GSH and CAT decrease in kidney tissues } \\
\text { as compared to unexposed controls. }\end{array}$ \\
\hline $\begin{array}{l}\text { Hussain } \\
\text { et al, } \\
2018^{115}\end{array}$ & $\begin{array}{l}\text { Male Wistar } \\
\text { Albino rats }\end{array}$ & $\begin{array}{l}\text { Rats were randomly divided into three groups: control }(n=8) \text {, } \\
\text { bakhour }(n=16) \text {, and oudh }(n=16) \text {. } \\
\text { Rats in bakhour and oudh groups were subjected to the whole- } \\
\text { body exposure of incense smoke generated from the burning of } \\
4 \mathrm{~g} \text { of respective incense for } 60 \text { min daily for } 30 \text { days; while } \\
\text { control rats were maintained in fresh air. Eight rats from each } \\
\text { group were then sacrificed at the end of } 30 \text {-day exposure. } \\
\text { Remaining eight rats from two exposed groups were suspended } \\
\text { to exposure of incense smoke, then sacrificed at } 30 \text { days after } \\
\text { the cessation of exposure. }\end{array}$ & $\begin{array}{l}\text { Rats exposed to incense smoke showed pronounced increase in } \\
\text { MDA and significant decrease in SOD as compared to unexposed } \\
\text { controls. } \\
\text { Cessation of incense smoke exposure yielded significant reversal } \\
\text { in the levels of markers after } 30 \text { days. }\end{array}$ \\
\hline $\begin{array}{l}\text { Kobayashi } \\
\text { et al, } \\
2010^{108}\end{array}$ & $\begin{array}{l}\text { Human } \\
\text { monocytes- } \\
\text { macrophages } \\
\text { U937 } \\
\text { Human Clara } \\
\text { cells } \mathrm{NCl}-\mathrm{H} 44 \mathrm{I}\end{array}$ & $\begin{array}{l}\text { Cells were treated with concentrations of I, } 2.5 \text {, and } 10 \mu g / m L \\
\text { particle equivalent organic extracts from incense source PM } \\
\text { samples for } 24 \mathrm{~h} \text {. }\end{array}$ & $\begin{array}{l}\text { Incense PM could induce strong effect on mRNA expression of } \\
\text { HO-I in U937 macrophages. } \\
\text { Dose-response relationship between incense PM exposure and } \\
\text { HO-I mRNA expression was found in both cell lines. }\end{array}$ \\
\hline
\end{tabular}

Abbreviations: CAT, catalase; GSH, glutathione; HO-I, heme oxygenase I; PM, particulate matter; PM2.5, the fine fraction of PM with aerodynamic diameter $\leq 2.5 \mu$ m; MDA, malondialdehyde; SOD, superoxide dismutase. 


\section{Pulmonary Oxidative Stress and Adverse Effects of Respiratory System Induced by Incense Smoke}

Air pollution refers to a heterogeneous mixture of gases (eg, carbon oxides, nitrogen oxides, and sulfur dioxide), particulate matter, and organic volatiles. ${ }^{122}$ Oxidative stress is one of pathophysiological mechanisms in response to air pollution exposure in animal models and humans. ${ }^{123}$ Considering the fact that air pollution is primarily introduced into the body through inhalation, the initial locus of oxidative stress is generally airways and lungs, known as pulmonary oxidative stress, subsequently triggering pulmonary inflammation and promoting lung damages. ${ }^{124}$ Indeed, there is a plethora of evidences linking air pollution-induced pulmonary oxidative stress with adverse outcomes of respiratory system. ${ }^{122,125}$ Since incense burning generally generates smoke consisting of constituents similar to air pollution, the paradigm of pulmonary oxidative stress can be the plausible basis of incense smoke-mediated toxicities. In fact, several exposure studies using different models have demonstrated the increased oxidative stress in pulmonary compartment that can further trigger inflammation and regulate downstream signaling pathways. It was reported that exposure to incense particles could induce oxidative stress that altered cell cycle regulation and cytoskeleton assembly, leading to apoptosis and cellular dysfunction in human alveolar epithelial A549 cells. ${ }^{114}$ Incense smoke has also been shown to trigger the expression of cytokines and chemokines in the respiratory epithelium, resulting in damages in the respiratory system. Interestingly, the upregulation of inflammatory molecules has been reported along with the pronounced alterations of oxidative stress markers. ${ }^{108,109}$ The significant generation of inflammatory markers, including interleukin-8 (IL-8) and cyclooxygenase-2 (COX-2), was found in both macrophage model and lung-derived cell lines following exposure to PM extracts from different types of incense. In accordance, the genes encoding these molecules were also upregulated. ${ }^{108}$ IL-8, as a potent neutrophil recruiting factor, has been implicated in the development of many respiratory diseases, ${ }^{126}$ whereas COX-2 has also long been regarded as a key factor in the pathogenesis of airway inflammation. ${ }^{127}$ Similarly, emissions from Arabian incense was found to induce inflammatory response in human epithelial A549 cells, as shown by the significant increase in relative expression levels of IL-8. ${ }^{11}$ Similarly, the markedly increased levels of several inflammatory markers in lung tissues were also observed in incense smoke-exposed rats. ${ }^{109}$ Neutrophils have been implicated in the pathogenesis of asthma and lung diseases, ${ }^{126}$ and Arabian incense exposure was found to induce the infiltration of neutrophils in pulmonary alveoli in rats. ${ }^{63}$ Collectively, the adverse effects of incense smoke on respiratory system appear to be driven by the induction of pulmonary oxidative stress. Clearly, the mechanisms by which pulmonary oxidative stress triggers inflammation and mediates downstream signaling pathways are yet to be fully understood, requiring further investigations. Moreover, in humans, the responses are complex which vary depending on many variables such as concentration, duration, deposition, distribution, sequestration, and host susceptibility, among others. ${ }^{128}$ By using the International Commission on Radiological Protection (ICRP) model, the deposition of metallic particles in the human respiratory tract from incense burning at temples was determined. It was observed that the total deposited flux ranged from $83 \%$ to $84.82 \%$ of total atmospheric metal concentration, with the highest rate was found in the head airway. ${ }^{100}$ Likewise, the personal exposure dose rates in the human respiratory tract due to incense burning were calculated using timeactivity and particle size distribution data collected from a traditional Taiwanese residence by modified ICRP model. The results found that the deeper lung region had a lower average particle mass lung/indoor ratio; meanwhile, the average integrated deposition dose rates were highest in the extrathoracic region, followed by the bronchiolar and bronchial regions. Importantly, the major deposition mechanism was suggested through the inertial impaction rate, by which the deposition rate increased with increased particle sizes and decreased airway diameters. ${ }^{101}$ The development of mechanistic dosimetry models is highly desirable to discover the deposition pattern and exposuredose-response relationships for incense smoke, thereby providing reliable tools for health risk assessment.

\section{Vascular Oxidative Stress and Cardiovascular Toxicities Induced by} Incense Smoke

The vascular endothelium is an essential barrier that modulates a multitude of exposures and prevents vascular inflammation and injuries through a diversity of paradigm, among which the generation of nitric oxide (NO) is the principal pathway. ${ }^{123}$ In the vasculature, ROS are produced by a number of sources such as mitochondria, 
NADPH oxidase, xanthine oxidase, and uncoupled endothelial nitric oxide synthase. Fortunately, the vasculature is prevented from deleterious effects of ROS by antioxidant defenses. However, cardiovascular risk factors may enhance ROS generation, resulting in oxidative stress if it exceeds the counteract capacity of antioxidant systems. ${ }^{129}$ The major ROS generated in response to stimuli is superoxide anion, which quickly combines with NO to produce peroxynitrite, decreasing NO bioavailability and leading to endothelial dysfunction. ${ }^{130}$ In this context, vascular oxidative stress may play pivotal roles in the initiation and progression of endothelial dysfunction which precedes many cardiovascular pathologies. Additionally, dysregulation of NO release may represent an important link between risk factors and cardiovascular diseases. Exposure to particle extracts from a temple in Taiwan was found to significantly increase interleukin 6 (IL-6) and endothelin-1 (ET-1) generation as well as to evidently decrease NO synthesis in human coronary artery endothelial cell model. ${ }^{70}$ Similar significant ET-1 increase and NO decrease were also observed in vascular tissues obtained from rat models that exposed to smoke emitted from incense burning. ${ }^{115}$ The proinflammatory molecule IL-6 has been well-documented to play central role in the pathophysiology of cardiovascular diseases, ${ }^{131}$ whereas ET-1 is a vasoconstrictor secreted by endothelial cells and acts as the natural antagonist of NO. ${ }^{132}$ Dysfunction of endothelium may result from ET-1 increase and/or NO decrease, ultimately leading to vascular morbidity and mortality. ${ }^{132}$ In vivo experiments have shown that the whole-body exposure of smoke emanated from incense burning may result in oxidative stress in rat heart tissues, as determined by the significant increase in the levels of oxidative stress marker along with the evident decrease in the levels of antioxidants. Moreover, the remarkably elevated levels of various chemokines and inflammatory mediators were also detected in heart tissues of rats exposed to incense smoke as opposed to unexposed controls, suggesting the increased infiltration of inflammatory mediators in heart tissues through direct immunologic response to incense smoke or indirect regulation by oxidative stress. The authors proposed that the increased gene expression of CYP1A1 and CYP1A2 may be instrumental in the incense smoke-induced oxidative stress and inflammation. ${ }^{68}$ All these evidences suggest that vascular oxidative stress and inflammation are direct sequelae of exposure to incense burning. It is clear that many gaps still exist. First, the routes by which constituents presenting in the incense smoke may enter the blood stream and affect the vasculature are unknown. Second, in-depth information on the regulation and expression of oxidant sources as well as antioxidant defenses in exposure models remains sparse. Third, the signaling pathways underlying vascular oxidative stress and cardiovascular effects of incense smoke are understudied.

\section{Future Studies in the Elucidation of the Role of Oxidative Stress in Systemic Toxicities Induced by Incense Smoke}

Early observation demonstrated that the whole-body exposure to incense smoke could trigger systemic oxidative stress and enhance systemic inflammation in rats. Interestingly, the cessation of exposure can lead to the significant reversal of examined markers. ${ }^{115}$ This finding highlights the potential that adverse health outcomes following exposure to incense burning may attribute to systemic oxidative stress. While the involvement of oxidative stress in pulmonary and vascular compartments have been gradually documented in literature, the role of this cellular state in mediating systemic effects induced by exposure to incense burning are yet to be elucidated.

\section{Implications for Public Health Management}

The adverse effects of incense burning on human health may have some important public health implications. The multi-aspect endeavor at various levels is required to be implemented for restricting the growing menace derived from this common practice.

\section{Guidelines for Safer Incense Use}

It is undoubtful that no individual and organization can invade the religious and spiritual freedom. A good way should be the cooperation between government and stakeholders, such as religious leaders and media, to disseminate the knowledge concerning potential effects of incense burning to the users, thereby increasing the awareness about this risk. Another option is that incense can be taxed by government to reduce the amount of incense use. In that case, however, the incense market can be flooded by contraband products made of cheap and unfriendly materials. Rather, the situation can be improved by establishing the guidelines for safer practice of incense burning. For instance, it was reported that the emission and health risk may differ among housing conditions, 
particularly ventilation. ${ }^{17,133,134}$ Thus, in cases where incense burning is unavoidable, every attempt must be made to improve the indoor air quality, such as reducing the amount of incense burned, enlarging the space, facilitating the ventilation, and selecting health-friendly incense products.

\section{Alternatives for Conventional Incense}

Since it is relatively impractical to discourage the incense use, the development of alternatives with less health risk is a potential approach. Under the same burning conditions, there was a positive correlation between the total metallic content with the burning rate, whereas it was a negative correlation between the total metallic content and the particulate matter emission. ${ }^{135}$ These results suggest that higher metallic content in the incense would effectively foster the combustion and reduce the harmful particulate emission. Indeed, it was calculated that when the total metallic content increased from $0.5 \%$ to $2 \%$, the particulate emission would be reduced by up to $40 \% .^{135}$ Therefore, incense manufacturers can optimize the raw materials in quantity and quality, such as total metal, to fabricate safer products. In addition to traditional incense burning, alternative electronic solutions can be introduced and adopted as an action for risk reduction. There are currently three main categories of electronic incense products, including 1) visual appearance simulation of traditional incense but no fire, smoke, and aroma; 2) visual and aromatic simulation but no smoke; and 3) health-friendly simulation of visual appearance and burning-like smoke and aroma emission. ${ }^{1}$ Through the application of electronic simulation of incense burning, users may still experience similar religious practice, setting up a bridge between spiritual life and physical health. However, religiosity can be the primary reason that incense users feel reluctant to use these alternative products. ${ }^{1}$ Interestingly, in the current 4.0 era, virtual incense practice through mobile apps might be expected to be applicable as a promising alternative. Clearly, the exploration of effective alternative solutions to promote health-friendly incense practice is a long and challenging journey.

\section{Antioxidant-Based Strategies}

Since oxidative stress is postulated as a major mechanism by which incense smoke elicits adverse effects on biological systems, antioxidants can be used as an adjuvant to reduce this risk. The clinical implications of oxidative stress and antioxidant-based strategies in many types of diseases have been documented. ${ }^{136-138}$ While the efficacy of antioxidants on the reduction of incense burning-related adverse effects still lack empirical findings, the positive role of healthy diet on the association between incense use and health risks has been suggested. In a cross-sectional investigation from Hong Kong, it was found that incense burning had no significant effect on lung cancer risk among non-smokers and even remarkably reduced risk among smokers after confounder adjustment. This unexpected finding was attributed to the information that incense use was associated with dietary habits with more fresh fish, more retinol, and less alcohol. ${ }^{59}$ Similarly, an earlier epidemiological study among Chinese female in Hong Kong attained the same observation, which was also explained by the relative better diets with higher intake of fresh fruits, vegetables, and fish. ${ }^{139}$ These preliminary data should have given idea to perform further investigations to explore the effectiveness of antioxidants on the impediment of health risks associated to incense burning, thereby providing a feasible and effective approach.

\section{Conclusion}

As a part of human culture and religion, incense is burned in many parts all over the world, especially in Asia. However, the use of incense was noticed as a potential risk to human well-being since the 1990s because of a research that indicated the higher genotoxicity of some incense smoke condensates in relation to that of tobacco smoke in mammalian cells. ${ }^{81}$ Moreover, earlier experiment found that burning per gram of incense led to a twice the emission rate of particulate matter as compared to cigarettes, ${ }^{140}$ while aerosols originated from incense burning were similar to those condensed from environmental tobacco smoke. ${ }^{141}$ Considering the popularity of incense practice worldwide, these preliminary data may have raised a concern about the threat of incense burning to human health in addition to tobacco smoking and air pollution. Now many evidences suggest that incense burning might affect all stages of lives, from pre-conception to old age, with multiple health effects. Much work has been done in order to explore the toxicities status of burning incense in association with human health. Although underlying mechanisms remain still in the primary stages of study, oxidative stress and associated inflammatory responses seem to be the plausible pathophysiological pathways underlying the adverse effects of incense smoke. Notably, tobacco smoking has been also well recognized an oxidative stressor that induces the accumulation of reactive oxygen species, which in turn leads to damages to the body. ${ }^{142}$ 
Since both incense smoke and tobacco smoke may affect the biological systems through the same pathway, it would not be surprising that the effects of incense smoke in ever or current smokers are different from those in never smokers, but in varying ways. For instance, more pronounced association between incense use and lung cancer in male smokers was documented in the literature. ${ }^{14}$ In contrast, lesser effects of incense burning on kidney function was observed in smokers who were already exposed to the strong and harmful substances from cigarette smoking as compared to non-smokers. ${ }^{19}$ In addition to incense smoke, incense stick ash is also of health concern as a product of burning process that needs more understanding. Summing up all the potential effects of incense use on human health and environmental ambience, further investigations in the future are desirable to be implemented. The more evaluation of incense products, the better measures to reduce their consequences. Clearly, this is an issue in which multidisciplinary effort is demanded.

\section{Acknowledgments}

We thank Dr Wei-Ning Lin for discussion and comments.

\section{Funding}

This work is supported by the Taipei Medical University Hospital, grant number 110TMU-TMUH-14, the Chang Gung Medical Research Foundation, grant number CMRP6J0051, and the Chang Gung University of Science and Technology, grant number ZRRPF3L0091 and ZRRPF3K0111.

\section{Disclosure}

The authors declare that there is no conflict of interest in this work.

\section{References}

1. Qin Z, Song Y, Jin Y. Green worship: the effects of devotional and behavioral factors on adopting electronic incense products in religious practices. Int $J$ Environ Res Public Health. 2019;16(19):3618. doi:10.3390/ijerph 16193618

2. Jetter JJ, Guo Z, McBrian JA, Flynn MR. Characterization of emissions from burning incense. Sci Total Environ. 2002;295(1-3):51-67. doi:10.1016/s0048-9697(02)00043-8

3. Yadav VK, Kumar P, Kalasariya H, et al. The current scenario of Indian incense sticks market and their impact on the Indian economy. Ind J Pure App Biosci. 2020;8(3):627-636. doi:10.18782/ 2582-2845.8168

4. Eggert T, Hansen OC. Survey of Chemical Substances in Consumer Products No. 39. Danish Environ Agency. 2004.

5. Yin H, Lin Q, You Z, Qiu J, Zhang E, Chen N. Investigation of an environmentally friendly incense consisting of soy-based adhesive and wood powder. BioRes. 2019;14(3):5097-5108.
6. Bureau KHCEP. Reduction of Pollutants in Temples. In: Total Inventory Control of Air Pollutants and the Guidance Program for Reduction. Kao-Hsiong, Taiwan: Bureau KHCEP; 2003:6-9.

7. Lin TC, Krishnaswamy G, Chi DS. Incense smoke: clinical, structural and molecular effects on airway disease. Clin $\mathrm{Mol}$ Allergy. 2008;6:3. doi:10.1186/1476-7961-6-3

8. Apte K, Salvi S. Household air pollution and its effects on health. F1000Res. 2016;5:F1000Faculty Rev-2593. doi:10.12688/ f1000research.7552.1

9. Yeatts KB, El-Sadig M, Leith D, et al. Indoor air pollutants and health in the United Arab Emirates. Environ Health Perspect. 2012;120(5):687-694. doi:10.1289/ehp.1104090

10. Yadav VK, Gnanamoorthy G, Cabral-Pinto MMS, et al. Variations and similarities in structural, chemical, and elemental properties on the ashes derived from the coal due to their combustion in open and controlled manner. Environ Sci Pollut Res Int. 2021;28(25):32609-32625. doi:10.1007/s11356-021-12989-5

11. Cohen R, Sexton KG, Yeatts KB. Hazard assessment of United Arab Emirates (UAE) incense smoke. Sci Total Environ. 2013;458-460:176-186. doi:10.1016/j.scitotenv.2013.03.101

12. Chen YC, Ho WC, Yu YH. Adolescent lung function associated with incense burning and other environmental exposures at home. Indoor Air. 2017;27(4):746-752. doi:10.1111/ina.12355

13. Pan A, Clark ML, Ang LW, Yu MC, Yuan JM, Koh WP. Incense use and cardiovascular mortality among Chinese in Singapore: the Singapore Chinese Health Study. Environ Health Perspect. 2014;122(12):1279-1284. doi:10.1289/ehp.1307662

14. Tse LA, Yu IT, Qiu H, Au JS, Wang XR. A case-referent study of lung cancer and incense smoke, smoking, and residential radon in Chinese men. Environ Health Perspect. 2011;119(11):1641-1646. doi: $10.1289 /$ ehp. 1002790

15. Friborg JT, Yuan JM, Wang R, Koh WP, Lee HP, Yu MC. Incense use and respiratory tract carcinomas: a prospective cohort study. Cancer. 2008;113(7):1676-1684. doi:10.1002/cncr.23788

16. Yadav VK, Singh B, Choudhary N. Characterization of Indian incense stick powders for their physical, chemical and mineralogical properties. World J Environ Biosci. 2020;9(1):39-43.

17. Ji X, Le Bihan O, Ramalho O, et al. Characterization of particles emitted by incense burning in an experimental house. Indoor Air. 2010;20(2):147-158. doi:10.1111/j.1600-0668.2009.00634.x

18. Lee SC, Wang B. Characteristics of emissions of air pollutants from burning of incense in a large environmental chamber. Atmos Environ. 2004;38(7):941-951. doi:10.1016/j.atmosenv.2003.11.002

19. Geng TT, Jafar TH, Yuan JM, Koh WP. Long-term incense use and the risk of end-stage renal disease among Chinese in Singapore: the Singapore Chinese health study. BMC Nephrol. 2019;20(1):9. doi:10.1186/s12882-018-1186-9

20. Yadav VK, Yadav KK, Gnanamoorthy G, et al. Green synthesis and characterization of polyhedral shaped amorphous iron oxide nanoparticles from incense sticks ash waste. Environ Technol Innov. 2020;20:101089. doi:10.1016/j.eti.2020.101089

21. Kalender SS, Alkan GB. Air Pollution. In: Hussain C editor. Handbook of Environmental Materials Management. Springer, Cham;2019.

22. Jilla A, Kura B. Particulate matter and carbon monoxide emission factors from incense burning. Environ Pollut Climate Change. 2017;1(4):140. doi:10.4172/2573-458X.1000140

23. Penney D, Benignus V, Kephalopoulos S, Dimitrios K, Michael K, Agnes V. Carbon Monoxide. In: WHO Guidelines for Indoor Air Quality: Selected Pollutants. Geneva: World Health Organization; 2010. Available from https://www.ncbi. nlm.nih.gov/books/NBK138710/. Accessed 31 Jun, 2021.

24. Rose JJ, Wang L, Xu Q, et al. Carbon monoxide poisoning: pathogenesis, management, and future directions of therapy. Am $J$ Respir Crit Care Med. 2017;195(5):596-606. doi:10.1164/ rccm.201606-1275CI 
25. Jarvis DJ, Adamkiewicz G, Heroux ME, Rapp R, Kelly FJ. Nitrogen Dioxide. In: WHO Guidelines for Indoor Air Quality: Selected Pollutants. Geneva: World Health Organization; 2010. Available from https:/www.ncbi.nlm.nih.gov/books/NBK138707/. Accessed 1 July, 2021.

26. Bootdee S, Chantara S. Emission of fine particulate matter and nitrogen dioxide from incense burning in shrines, Chiang Mai, Thailand. Int J Environ Sci Dev. 2014;5:228-232. doi:10.7763/ IJESD.2014.V5.483

27. National Research Council (US) Committee on Toxicology. Sulfur Dioxide. In: Emergency and Continuous Exposure Limits for Selected Airborne Contaminants. Vol. 2. Washington (DC): National Academies Press (US); 1984. Availble from: https:// www.ncbi.nlm.nih.gov/books/NBK208295/. Accessed 1 July, 2021 .

28. Ali MU, Liu G, Yousaf B, Ullah H, Abbas Q, Munir MAM. A systematic review on global pollution status of particulate matter-associated potential toxic elements and health perspectives in urban environment. Environ Geochem Health. 2019;41 (3):1131-1162. doi:10.1007/s10653-018-0203-z

29. Fang GC, Chang $\mathrm{CN}$, Chu CC, et al. Fine (PM2.5), coarse (PM2.5-10), and metallic elements of suspended particulates for incense burning at Tzu Yun Yen temple in central Taiwan. Chemosphere. 2003;51(9):983-991. doi:10.1016/S0045-6535(03) 00124-3

30. Fang GC, Chang CN, Wu YS, Yang CJ, Chang SC, Yang IL. Suspended particulate variations and mass size distributions of incense burning at Tzu Yun Yen temple in Taiwan, Taichung. Sci Total Environ. 2002;299(1-3):79-87. doi:10.1016/s00489697(02)00227-9

31. Lung SC, Kao MC. Worshippers' exposure to particulate matter in two temples in Taiwan. J Air Waste Manag Assoc. 2003;53 (2):130-135. doi:10.1080/10473289.2003.10466140

32. Fang GC, Lin SJ, Lee JF, Chang CC. A study of particulates and metallic element concentrations in temple. Toxicol Ind Health. 2009;25(2):93-100. doi:10.1177/0748233709105594

33. Mannix RC, Nguyen KP, Tan EW, Ho EE, Phalen RF. Physical characterization of incense aerosols. Sci Total Environ. 1996;193 (2):149-158. doi:10.1016/s0048-9697(96)05343-0

34. Nemmar A, Holme JA, Rosas I, Schwarze PE, Alfaro-Moreno E. Recent advances in particulate matter and nanoparticle toxicology: a review of the in vivo and in vitro studies. Biomed Res Int. 2013;2013:279371. doi:10.1155/2013/279371

35. Dominici F, Peng RD, Bell ML, et al. Fine particulate air pollution and hospital admission for cardiovascular and respiratory diseases. JAMA. 2006;295(10):1127-1134. doi:10.1001/ jama.295.10.1127

36. World Health Organization. Ambient (outdoor) air pollution. Available from: https://www.who.int/news-room/fact-sheets /detail/ambient-(outdoor)-air-quality-and-health. Accessed June 31, 2021.

37. Lee CW, Vo TTT, Wu CZ, et al. The inducible role of ambient particulate matter in cancer progression via oxidative stress-mediated reactive oxygen species pathways: a recent perception. Cancers. 2020;12(9):2505. doi:10.3390/ cancers 12092505

38. Ho SS, Yu JZ. Concentrations of formaldehyde and other carbonyls in environments affected by incense burning. J Environ Monit. 2002;4(5):728-733. doi:10.1039/b200998f

39. Zhang JP, Chen WJ, Li JN, Yu SJ, Zhao WJ. VOCs and particulate pollution due to incense burning in temples, China. Procedia Eng. 2015;121:992-1000. doi:10.1016/j.proeng.2015.09.067

40. Yang TT, Lin TS, Chang M. Characteristics of emissions of volatile organic compounds from smoldering incense. Bull Environ Contam Toxicol. 2007;78(5):308-313. doi:10.1007/ s00128-007-9184-9
41. Nicolas M, Buiron D, Quivet E, Albinet A, Karr G, Maupetit F Field campaign characterization of incense and candle emissions in indoor environment. International Conference on Indoor Air Quality and Climate (Indoor Air 2016), Ghent, Belgium. 2016; ffineris-01863022.

42. Mahgoub H, Salih NA. Concentration level of polycyclic aromatic hydrocarbons emitted from Oud incense: al-Baha city, Southwest Saudi Arabia. Mod Chem Appl. 2017;5. doi:10.4172/ 2329-6798.1000201

43. Lin TC, Chang FH, Hsieh JH, Chao HR, Chao MR. Characteristics of polycyclic aromatic hydrocarbons and total suspended particulate in indoor and outdoor atmosphere of a Taiwanese temple. J Hazard Mater. 2002;95(1-2):1-12. doi:10.1016/s0304-3894(02)00146-2

44. Lung SC, Kao MC, Hu SC. Contribution of incense burning to indoor PM10 and particle-bound polycyclic aromatic hydrocarbons under two ventilation conditions. Indoor Air. 2003;13 (2):194-199. doi:10.1034/j.1600-0668.2003.00197.x

45. Bootdee S, Chantara S, Prapamontol T. Determination of PM2.5 and polycyclic aromatic hydrocarbons from incense burning emission at shrine for health risk assessment. Atmos Pollut Res. 2016;7(4):680-689. doi:10.1016/j.apr.2016.03.002

46. World Health Organization. Air Pollution and Cancer. IARC Scientific Publication No. 161. Available from: https:/www.iarc. who.int/wp-content/uploads/2018/07/AirPollutionandCancer161. pdf. Accessed July 2, 2021.

47. O'Brien PJ, Siraki AG, Shangari N. Aldehyde sources, metabolism, molecular toxicity mechanisms, and possible effects on human health. Crit Rev Toxicol. 2005;35(7):609-662. doi:10.1080/10408440591002183

48. Masekameni MD, Moolla R, Gulumian M, Brouwer D. Risk assessment of benzene, toluene, ethyl benzene, and xylene concentrations from the combustion of coal in a controlled laboratory environment. Int J Environ Res Public Health. 2018;16(1):95. doi:10.3390/ijerph16010095

49. Kim KH, Jahan SA, Kabir E, Brown RJ. A review of airborne polycyclic aromatic hydrocarbons (PAHs) and their human health effects. Environ Int. 2013;60:71-80. doi:10.1016/j. envint.2013.07.019

50. Hayakawa R, Matsunaga K, Arima Y. Depigmented contact dermatitis due to incense. Contact Dermatitis. 1987;16(5):272-274. doi:10.1111/j.1600-0536.1987.tb01451.x

51. Hayakawa R, Matsunaga K, Arima Y. Airborne pigmented contact dermatitis due to musk ambrette in incense. Contact Dermatitis. 1987;16(2):96-98. doi:10.1111/j.1600-0536.1987. tb01387.x

52. Ho CK, Tseng WR, Yang CY. Adverse respiratory and irritant health effects in temple workers in Taiwan. $J$ Toxicol Environ Health A. 2005;68(17-18):1465-1470. doi:10.1080/152873905 90967405

53. Norbäck D, Zhang X, Fan Q, et al. Home environment and health: domestic risk factors for rhinitis, throat symptoms and non-respiratory symptoms among adults across China. Sci Total Environ. 2019;681:320-330. doi:10.1016/j.scitotenv.2019.05.084

54. Hsu NY, Wang JY, Wu PC, Su HJ. Paternal heredity and housing characteristics affect childhood asthma and allergy morbidity. Arch Environ Occup Health. 2012;67(3):155-162. doi:10.1080/ 19338244.2011.598890

55. Zhang Z, Tan L, Huss A, et al. Household incense burning and children's respiratory health: a cohort study in Hong Kong. Pediatr Pulmonol. 2019;54(4):399-404. doi:10.1002/ppul.24251

56. Yang CY, Chiu JF, Cheng MF, Lin MC. Effects of indoor environmental factors on respiratory health of children in a subtropical climate. Environ Res. 1997;75(1):49-55. doi:10.1006/ enrs.1997.3774 
57. Al-Rawas OA, Al-Maniri AA, Al-Riyami BM. Home exposure to Arabian incense (bakhour) and asthma symptoms in children: a community survey in two regions in Oman. BMC Pulm Med. 2009;9:23. doi:10.1186/1471-2466-9-23

58. Wang IJ, Tsai CH, Chen CH, Tung KY, Lee YL. Glutathione S-transferase, incense burning and asthma in children. Eur Respir J. 2011;37(6):1371-1377. doi:10.1183/09031936.00137210

59. Koo LC, Ho JC, Tominaga S, et al. Is Chinese incense smoke hazardous to respiratory health?: epidemiological results from Hong Kong. Indoor Environ. 1995;4(6):334-343. doi:10.1177/ 1420326X9500400604

60. Guo SE, Chi MC, Lin CM, Yang TM. Contributions of burning incense on indoor air pollution levels and on the health status of patients with chronic obstructive pulmonary disease. PeerJ. 2020;8:e9768. doi:10.7717/peerj.9768

61. Døssing M, Khan J, al-Rabiah F. Risk factors for chronic obstructive lung disease in Saudi Arabia. Respir Med. 1994;88 (7):519-522. doi:10.1016/s0954-6111(05)80334-8

62. Alarifi SA, Mubarak M, Alokail MS. Ultrastructure of the pulmonary alveolar cells of rats exposed to Arabian mix incense (Ma`amoul). J Biol Sci. 2004;4(6):694-699. doi:10.3923/ jbs.2004.694.699

63. Alarifi SA, Mubarak MM, Alokail MS. Ultrastructural changes of pneumocytes of rat exposed to Arabian incense (Bakhour). Saudi Med J. 2004;25(11):1689-1693.

64. Kammoolkon R, Taneepanichskul N, Pitaknoppakul N, Lertmaharit S, Lohsoonthorn V. Incense smoke and increasing carotid intima media thickness: a cross-sectional study of the Thai-Vietnamese community. Asia Pac J Public Health. 2018;30 (2):178-187. doi:10.1177/1010539517753930

65. Kasliwal RR, Bansal M, Desai D, Sharma M. Carotid intima-media thickness: current evidence, practices, and Indian experience. Indian $J$ Endocrinol Metab. 2014;18(1):13-22. doi:10.4103/2230-8210.126522

66. Huang YL, Chen HW, Han BC, et al. Personal exposure to household particulate matter, household activities and heart rate variability among housewives. PLoS One. 2014;9(3):e89969. doi:10.1371/journal.pone.0089969

67. Alokail MS, Al-Daghri NM, Alarifi SA, Draz HM, Hussain T, Yakout SM. Long-term exposure to incense smoke alters metabolism in Wistar albino rats. Cell Biochem Funct. 2011;29 (2):96-101. doi:10.1002/cbf.1726

68. Al-Attas OS, Hussain T, Ahmed M, et al. Ultrastructural changes, increased oxidative stress, inflammation, and altered cardiac hypertrophic gene expressions in heart tissues of rats exposed to incense smoke. Environ Sci Pollut Res Int. 2015;22 (13):10083-10093. doi:10.1007/s11356-015-4212-5

69. Weber LP, Al-Dissi A, Marit JS, German TN, Terletski SD. Role of carbon monoxide in impaired endothelial function mediated by acute second-hand tobacco, incense, and candle smoke exposures. Environ Toxicol Pharmacol. 2011;31(3):453-459. doi:10.1016/j. etap.2011.02.008

70. Lin LY, Lin HY, Chen HW, Su TL, Huang LC, Chuang KJ. Effects of temple particles on inflammation and endothelial cell response. Sci Total Environ. 2012;414:68-72. doi:10.1016/j. scitotenv.2011.08.050

71. Song X, Ma W, Xu X, et al. The Association of Domestic Incense Burning with Hypertension and Blood Pressure in Guangdong, China. Int $J$ Environ Res Public Health. 2017;14(7):788. doi:10.3390/ijerph14070788

72. He JR, Wei DM, Chan FF, et al. Associations between maternal exposure to incense burning and blood pressure during pregnancy. Sci Total Environ. 2018;610-611:1421-1427. doi:10.1016/j. scitotenv.2017.08.134
73. Wong A, Lou W, Ho KF, et al. Indoor incense burning impacts cognitive functions and brain functional connectivity in community older adults. Sci Rep. 2020;10(1):7090. doi:10.1038/s41598020-63568-6

74. Fang XY, Strodl E, Liu BQ, et al. Association between prenatal exposure to household inhalants exposure and ADHD-like behaviors at around 3 years of age: findings from Shenzhen Longhua Child Cohort Study. Environ Res. 2019;177:108612. doi:10.1016/ j.envres.2019.108612

75. Wei CF, Chen MH, Lin CC, et al. Household incense burning and infant gross motor development: results from the Taiwan Birth Cohort Study. Environ Int. 2018;115:110-116. doi:10.1016/j. envint.2018.03.005

76. Chen LY, Ho C. Incense burning during pregnancy and birth weight and head circumference among term births: the Taiwan Birth Cohort Study. Environ Health Perspect. 2016;124 (9):1487-1492. doi:10.1289/ehp.1509922

77. Chattopadhyay N, Mitra K. Neurodevelopmental outcome of high risk newborns discharged from special care baby units in a rural district in India. J Public Health Res. 2015;4(1):318. doi:10.4081/ jphr.2015.318

78. Tian Y, Zhang C, Yu G, Hu X, Pu Z, Ma L. Influencing factors of the neurodevelopment of high-risk infants. Gen Psychiatr. 2018;31(3):e100034. doi:10.1136/gpsych-2018-100034

79. Zhou R, An Q, Pan XW, Yang B, Hu J, Wang YH. Higher cytotoxicity and genotoxicity of burning incense than cigarette. Environ Chem Lett. 2015;13:465-471. doi:10.1007/s10311-0150521-7

80. Chang HL, Kuo ML, Lin JM. Mutagenic activity of incense smoke in comparison to formaldehyde and acetaldehyde in Salmonella typhimurium TA102. Bull Environ Contam Toxicol. 1997;58(3):394-401. doi:10.1007/s001289900347

81. Chen CC, Lee H. Genotoxicity and DNA adduct formation of incense smoke condensates: comparison with environmental tobacco smoke condensates. Mutat Res. 1996;367(3):105-114. doi:10.1016/0165-1218(95)00067-4

82. MacLennan R, Da Costa J, Day NE, Law CH, Ng YK, Shanmugaratnam K. Risk factors for lung cancer in Singapore Chinese, a population with high female incidence rates. Int J Cancer. 1977;20(6):854-860. doi:10.1002/ijc.2910200606

83. Chan-Yeung M, Koo LC, Ho JC, et al. Risk factors associated with lung cancer in Hong Kong. Lung Cancer. 2003;40 (2):131-140. doi:10.1016/s0169-5002(03)00036-9

84. Tang L, Lim WY, Eng P, et al. Lung cancer in Chinese women: evidence for an interaction between tobacco smoking and exposure to inhalants in the indoor environment. Environ Health Perspect. 2010;118(9):1257-1260. doi:10.1289/ehp.0901587

85. Xie SH, Yu IT, Tse LA, et al. Domestic incense burning and nasopharyngeal carcinoma: a case-control study in Hong Kong Chinese. Environ Mol Mutagen. 2014;55(9):751-756. doi:10.1002/em.21894

86. He YQ, Xue WQ, Shen GP, Tang LL, Zeng YX, Jia WH. Household inhalants exposure and nasopharyngeal carcinoma risk: a large-scale case-control study in Guangdong, China. BMC Cancer. 2015;15:1022. doi:10.1186/s12885-015-2035-x

87. Lowengart RA, Peters JM, Cicioni C, et al. Childhood leukemia and parents' occupational and home exposures. $J$ Natl Cancer Inst. 1987;79(1):39-46.

88. Preston-Martin S, Yu MC, Benton B, Henderson BE. N-Nitroso compounds and childhood brain tumors: a case-control study. Cancer Res. 1982;42(12):5240-5245.

89. Kuijten RR, Bunin GR, Nass CC, Meadows AT. Gestational and familial risk factors for childhood astrocytoma: results of a case-control study. Cancer Res. 1990;50(9):2608-2612. 
90. Bunin GR, Buckley JD, Boesel CP, Rorke LB, Meadows AT. Risk factors for astrocytic glioma and primitive neuroectodermal tumor of the brain in young children: a report from the Children's Cancer Group. Cancer Epidemiol Biomarkers Prev. 1994;3(3):197-204.

91. Hung DZ, Yang KW, Wu CC, Hung YH. Lead poisoning due to incense burning: an outbreak in a family. Clin Toxicol. 2020;1-6. doi:10.1080/15563650.2020.1853146

92. Hwang YH, Lin YS, Lin CY, Wang IJ. Incense burning at home and the blood lead level of preschoolers in Taiwan. Environ Sci Pollut Res Int. 2014;21(23):13480-13487. doi:10.1007/s11356014-3273-1

93. Hussain T, Al-Attas OS, Alrokayan SA, et al. Deleterious effects of incense smoke exposure on kidney function and architecture in male albino rats. Inhal Toxicol. 2016;28(8):364-373. doi:10.1080/ 08958378.2016.1179372

94. Sies H, Berndt C, Jones DP. Oxidative stress. Annu Rev Biochem. 2017;86:715-748. doi:10.1146/annurev-biochem-061516-045037

95. Sies H. On the history of oxidative stress: concept and some aspects of current development. Curr Opin Toxicol. 2018;7:122-126. doi:10.1016/j.cotox.2018.01.002

96. Pizzino G, Irrera N, Cucinotta M, et al. Oxidative stress: harms and benefits for human health. Oxid Med Cell Longev. 2017;2017:8416763. doi:10.1155/2017/8416763

97. Sies H, Jones DP. Reactive oxygen species (ROS) as pleiotropic physiological signalling agents. Nat Rev Mol Cell Biol. 2020;21 (7):363-383. doi:10.1038/s41580-020-0230-3

98. Sies H. Oxidative stress: oxidants and antioxidants. Exp Physiol. 1997;82(2):291-295. doi:10.1113/expphysiol.1997.sp004024

99. Bhattacharyya A, Chattopadhyay R, Mitra S, Crowe SE. Oxidative stress: an essential factor in the pathogenesis of gastrointestinal mucosal diseases. Physiol Rev. 2014;94(2):329-354. doi:10.1152/physrev.00040.2012

100. Chen KF, Tsai YP, Lai CH, Xiang YK, Chuang KY, Zhu ZH. Human health-risk assessment based on chronic exposure to the carbonyl compounds and metals emitted by burning incense at temples. Environ Sci Pollut Res Int. 2020;2:154.

101. Liao CM, Chen SC, Chen JW, Liang HM. Contributions of Chinese-style cooking and incense burning to personal exposure and residential PM concentrations in Taiwan region. Sci Total Environ. 2006;358(1-3):72-84. doi:10.1016/j.scitotenv.2005.03.026

102. Chuang HC, Jones TP, Lung SC, BéruBé KA. Soot-driven reactive oxygen species formation from incense burning. Sci Total Environ. 2011;409(22):4781-4787. doi:10.1016/j.scitotenv.2011.07.041

103. Chuang HC, Jones T, Chen Y, Bell J, Wenger J, BéruBé K. Characterisation of airborne particles and associated organic components produced from incense burning. Anal Bioanal Chem. 2011;401(10):3095-3102. doi:10.1007/s00216-011-5209-7

104. Tran TC, Marriott PJ. Comprehensive two-dimensional gas chromatography - time-of-flight mass spectrometry and simultaneous electron capture detection/nitrogen phosphorous detection for incense analysis. Atmos Environ. 2008;42:7360-7372. doi:10.1016/j.atmosenv.2008.06.028

105. Semchyshyn HM. Reactive carbonyl species in vivo: generation and dual biological effects. Sci World J. 2014;2014:417842. doi:10.1155/2014/417842

106. Bolton JL, Dunlap T. Formation and biological targets of quinones: cytotoxic versus cytoprotective effects. Chem Res Toxicol. 2017;30(1):13-37. doi:10.1021/acs.chemrestox.6b00256

107. Aust SD, Morehouse LA, Thomas CE. Role of metals in oxygen radical reactions. J Free Radic Biol Med. 1985;1(1):3-25. doi:10.1016/0748-5514(85)90025-x

108. Kobayashi R, Liu X, Wong P, et al. Assessment of health impacts of particulate matter from indoor air sources phase I: development of in vitro methodology; 2010. Available from: https://ww2.arb. ca.gov/sites/default/files/classic//research/apr/past/05-302.pdf. Accessed July 2, 2021.
109. Hussain T, Al-Attas OS, Al-Daghri NM, et al. Induction of CYP1A1, CYP1A2, CYP1B1, increased oxidative stress and inflammation in the lung and liver tissues of rats exposed to incense smoke. Mol Cell Biochem. 2014;391(1-2):127-136. doi:10.1007/s11010-014-1995-5

110. Sies H. Oxidative stress: concept and some practical aspects. Antioxidants. 2020;9(9):852. doi:10.3390/antiox9090852

111. Ighodaro OM, Akinloye OA. First line defence antioxidants-superoxide dismutase (SOD), catalase (CAT) and glutathione peroxidase (GPX): their fundamental role in the entire antioxidant defence grid. Alexandria J Med. 2018;54(4):287-293. doi:10.1016/j.ajme.2017.09.001

112. Aquilano K, Baldelli S, Ciriolo MR. Glutathione: new roles in redox signaling for an old antioxidant. Front Pharmacol. 2014;5:196. doi:10.3389/fphar.2014.00196

113. Ji LL, Yeo D. Oxidative stress: an evolving definition. Fac Rev. 2021;10:13. doi:10.12703/r/10-13

114. Chuang HC, Jones T, Chen TT, BéruBé K. Cytotoxic effects of incense particles in relation to oxidative stress, the cell cycle and F-actin assembly. Toxicol Lett. 2013;220(3):229-237. doi:10.1016/j.toxlet.2013.05.004

115. Hussain T, Alamery S, Dikshit G, Mohammed AA, Naushad SM, Alrokayan S. Incense smoke exposure augments systemic oxidative stress, inflammation and endothelial dysfunction in male albino rats. Toxicol Mech Methods. 2019;29(3):211-218. doi:10.1080/15376516.2018.1544681

116. Singh Z, Karthigesu I, Singh P, Kaur R. Use of malondialdehyde as a biomarker for assessing oxidative stress in different disease pathologies: a review. Iran J Public Health. 2014;43:7-16.

117. Niu X, Jones T, BéruBé K, Chuang HC, Sun J, Ho KF. The oxidative capacity of indoor source combustion derived particulate matter and resulting respiratory toxicity. Sci Total Environ. 2021;767:144391. doi:10.1016/j.scitotenv.2020.144391

118. Navasumrit P, Arayasiri M, Hiang OM, et al. Potential health effects of exposure to carcinogenic compounds in incense smoke in temple workers. Chem Biol Interact. 2008;173(1):19-31. doi:10.1016/j.cbi.2008.02.004

119. Menck CF, Munford V. DNA repair diseases: what do they tell us about cancer and aging? Genet Mol Biol. 2014;37(1 Suppl):220-233. doi:10.1590/s1415-47572014000200008

120. Paz-Elizur T, Sevilya Z, Leitner-Dagan Y, Elinger D, Roisman LC, Livneh Z. DNA repair of oxidative DNA damage in human carcinogenesis: potential application for cancer risk assessment and prevention. Cancer Lett. 2008;266(1):60-72. doi:10.1016/j.canlet.2008.02.032

121. Cooke MS, Evans MD, Dizdaroglu M, Lunec J. Oxidative DNA damage: mechanisms, mutation, and disease. FASEB J. 2003;17 (10):1195-1214. doi:10.1096/fj.02-0752rev

122. Haberzettl P, Bhatnagar A, Conklin DJ. Particulate Matter and Oxidative Stress - pulmonary and Cardiovascular Targets and Consequences, In: Laher I, editor. Systems Biology of Free Radicals and Antioxidants. Berlin, Heidelberg: Springer; 2014. Available from. Accessed 3 July, 2021.

123. Gangwar RS, Bevan GH, Palanivel R, Das L, Rajagopalan S. Oxidative stress pathways of air pollution mediated toxicity: recent insights. Redox Biol. 2020;34:101545. doi:10.1016/j. redox.2020.101545

124. Valavanidis A, Vlachogianni T, Fiotakis K, Loridas S. Pulmonary oxidative stress, inflammation and cancer: respirable particulate matter, fibrous dusts and ozone as major causes of lung carcinogenesis through reactive oxygen species mechanisms. Int $J$ Environ Res Public Health. 2013;10(9):3886-3907. doi:10.3390/ijerph10093886

125. Rao X, Zhong J, Brook RD, Rajagopalan S. Effect of particulate matter air pollution on cardiovascular oxidative stress pathways. Antioxid Redox Signal. 2018;28(9):797-818. doi:10.1089/ ars.2017.7394 
126. Pease JE, Sabroe I. The role of interleukin- 8 and its receptors in inflammatory lung disease: implications for therapy. Am J Respir Med. 2002;1(1):19-25. doi:10.1007/BF03257159

127. Rumzhum NN, Ammit AJ. Cyclooxygenase 2: its regulation, role and impact in airway inflammation. Clin Exp Allergy. 2016;46 (3):397-410. doi:10.1111/cea.12697

128. Simkhovich BZ, Kleinman MT, Kloner RA. Air pollution and cardiovascular injury epidemiology, toxicology, and mechanisms. $J$ Am Coll Cardiol. 2008;52(9):719-726. doi:10.1016/j. jacc.2008.05.029

129. Li H, Horke S, Förstermann U. Vascular oxidative stress, nitric oxide and atherosclerosis. Atherosclerosis. 2014;237(1):208-219. doi:10.1016/j.atherosclerosis.2014.09.001

130. Sena CM, Leandro A, Azul L, Seiça R, Perry G. Vascular oxidative stress: impact and therapeutic approaches. Front Physiol. 2018;9:1668. doi:10.3389/fphys.2018.01668

131. Kanda T, Takahashi T. Interleukin-6 and cardiovascular diseases. Jpn Heart J. 2004;45(2):183-193. doi:10.1536/jhj.45.183

132. Marasciulo FL, Montagnani M, Potenza MA. Endothelin-1: the yin and yang on vascular function. Curr Med Chem. 2006;13 (14):1655-1665. doi:10.2174/092986706777441968

133. Manoukian A, Quivet E, Temime-Roussel B, Nicolas M, Maupetit F, Wortham H. Emission characteristics of air pollutants from incense and candle burning in indoor atmospheres. Environ Sci Pollut Res Int. 2013;20(7):4659-4670. doi:10.1007/s11356012-1394-y

134. Manoukian A, Buiron D, Temime-Roussel B, Wortham H, Quivet E. Measurements of VOC/SVOC emission factors from burning incenses in an environmental test chamber: influence of temperature, relative humidity, and air exchange rate. Environ Sci Pollut Res Int. 2016;23(7):6300-6311. doi:10.1007/s11356-015-5819-2
135. Lin TC, Yang CR, Chang FH. Burning characteristics and emission products related to metallic content in incense. J Hazard Mater. 2007;140(1-2):165-172. doi:10.1016/j.jhazmat.2006.0 6.052

136. Dryden GW, Deaciuc I, Arteel G, McClain CJ. Clinical implications of oxidative stress and antioxidant therapy. Curr Gastroenterol Rep. 2005;7(4):308-316. doi:10.1007/s11894-0050024-y

137. Christofidou-Solomidou M, Muzykantov VR. Antioxidant strategies in respiratory medicine. Treat Respir Med. 2006;5(1):47-78. doi:10.2165/00151829-200605010-00004

138. Wang W, Kang PM. Oxidative stress and antioxidant treatments in cardiovascular diseases. Antioxidants. 2020;9(12):1292. doi:10.3390/antiox9121292

139. Koo LC, Ho JH. Diet as a confounder of the association between air pollution and female lung cancer: hong Kong studies on exposures to environmental tobacco smoke, incense, and cooking fumes as examples. Lung Cancer. 1996;14(Suppl 1):S47-S61. doi:10.1016/s0169-5002(96)90210-x

140. Löfroth G, Stensman C, Brandhorst-Satzkorn M. Indoor sources of mutagenic aerosol particulate matter: smoking, cooking and incense burning. Mutat Res. 1991;261(1):21-28. doi:10.1016/ 0165-1218(91)90094-3

141. Cheng YS, Bechtold WE, Yu CC, Hung IF. Incense smoke: characterization and dynamics in indoor environments. Aerosol Sci Technol. 1995;23(3):271-281. doi:10.1080/027868295 08965312

142. Caliri AW, Tommasi S, Besaratinia A. Relationships among smoking, oxidative stress, inflammation, macromolecular damage, and cancer. Mutat Res Rev Mutat Res. 2021;787:108365. doi:10.1016/j. mrrev.2021.108365
Journal of Inflammation Research

\section{Publish your work in this journal}

The Journal of Inflammation Research is an international, peerreviewed open-access journal that welcomes laboratory and clinical findings on the molecular basis, cell biology and pharmacology of inflammation including original research, reviews, symposium reports, hypothesis formation and commentaries on: acute/chronic inflammation; mediators of inflammation; cellular processes; molecular

\section{Dovepress}

mechanisms; pharmacology and novel anti-inflammatory drugs; clinical conditions involving inflammation. The manuscript management system is completely online and includes a very quick and fair peerreview system. Visit http://www.dovepress.com/testimonials.php to read real quotes from published authors. 